\title{
Porous Silica-Pillared MXenes with Controllable Interlayer Distances for Long-life Na-ion Batteries
}

Philip A. Maughan ${ }^{1}$, Valerie R. Seymour ${ }^{2}$, Ramon Bernardo-Gavito ${ }^{3}$, Daniel J. Kelly ${ }^{4}$, Shouqi Shao ${ }^{4}$, Supakorn Tantisriyanurak ${ }^{5}$, Robert Dawson ${ }^{5}$, Sarah J. Haigh ${ }^{4}$, Robert J. Young ${ }^{3}$, Nuria Tapia-Ruiz ${ }^{2}$, and Nuno Bimbo ${ }^{*}$

1 Department of Engineering, Lancaster University, Lancaster, LA1 4YW UK

2 Department of Chemistry, Lancaster University, Lancaster, LA1 4YB, UK

3 Department of Physics, Lancaster University, Lancaster, LA1 4YB, UK

4 School of Materials, University of Manchester, Manchester, M13 9PL UK

5 Department of Chemistry, University of Sheffield, Sheffield, S3 7HF UK.

* Corresponding Author: n.bimbo@lancaster.ac.uk

\section{Abstract}

MXenes are a recently discovered class of two-dimensional materials that have shown great potential as electrodes in electrochemical energy storage devices. Despite their promise in this area, MXenes can still suffer limitations in the form of restricted ion accessibility between the closely spaced multistacked MXene layers causing low capacities and poor cycle life. Pillaring, where a secondary species is inserted between layers, has been used to increase interlayer spacings in clays with great success, but has had limited application in MXenes. We report a new amine-assisted pillaring methodology that successfully intercalates silica-based pillars between $\mathrm{Ti}_{3} \mathrm{C}_{2}$ layers. Using this technique, the interlayer spacing can be controlled with the choice of amine and calcination temperature, up to a maximum of $3.2 \mathrm{~nm}$, the largest interlayer spacing reported for an MXene. Another effect of the pillaring is a dramatic increase in surface area, achieving BET surface areas of $235 \mathrm{~m}^{2} \mathrm{~g}^{-1}$, a sixty-fold increase over the unpillared material and the highest reported for MXenes using an intercalation-based method. The intercalation mechanism was revealed by different characterisation techniques, allowing the surface chemistry to be optimised for the pillaring process. The porous MXene was tested for Na-ion battery applications, and showed superior capacity, rate capability and remarkable stability compared with the non-pillared materials, retaining $98.5 \%$ capacity between the $50^{\text {th }}$ and $100^{\text {th }}$ cycles. These results demonstrate the applicability and promise of pillaring techniques applied to MXenes providing a new approach to optimising their properties for a range of applications, including energy storage, conversion, catalysis and gas separations.

\section{Keywords}

2D materials, porous materials, pillaring, MXene, Na-ion battery, energy storage, silica.

\section{Introduction}

MXenes are a recently discovered group of two-dimensional materials with the general formula $M_{n+1} X_{n} T_{x}$, where $M$ is an early transition metal, $X$ is carbon and/or nitrogen and $T_{x}$ are surface functional groups, which are typically $\mathrm{O}, \mathrm{OH}, \mathrm{F}$ or $\mathrm{Cl}^{1-3}$ MXenes have been employed as active materials in a variety of applications, such as batteries, supercapacitors, fuel cells, water desalination and purification, and catalysis, with great success. ${ }^{4-6}$ This is due to their unique combination of properties such as high electrical and thermal conductivity, hydrophilic nature and high chemical stability. ${ }^{4,6,7}$ As such, they combine the advantages of graphene (high conductivity and stability but hydrophobic) and graphene oxide (high stability, surface functional groups and hydrophilic but lower conductivity) in one material. However, like many other 2D materials MXenes suffer from challenges associated with maintaining the properties and performance of the $2 \mathrm{D}$ nanosheets when combining them into stable 3D architectures. Common problems are comparatively poor performances when in multi-layered form and a reduction in surface area due to the restacking of nanosheets over time. ${ }^{8}$ 
In addition, the specific surface areas of MXenes $\left(4-20 \mathrm{~m}^{2} \mathrm{~g}^{-1}\right)^{9-11}$ are significantly smaller than those of other 2D materials (300-2,000 $\mathrm{m}^{2} \mathrm{~g}^{-1}$ for graphene/graphene oxide materials) ${ }^{12-14}$ which limits their suitability for applications in energy storage, catalysis and gas capture and storage. Even when fully delaminated, the reported specific surface areas are no greater than $98 \mathrm{~m}^{2} \mathrm{~g}^{-1}$. ${ }^{15}$ Furthermore, the delaminated nanosheets tend to restack over time, leading to reduced performance, for example in a lithium-ion battery. ${ }^{15}$

One method for overcoming these issues involves introducing secondary species between the MXene's layers, resulting in increased interlayer spacings and therefore higher surface areas. In addition, the secondary species act as buffers between different flakes, preventing the restacking of the MXene layers, which improves the long term stability. To date, a number of different strategies have been reported, including the use of nanocarbon spacers, ${ }^{16,17}$ deliberate oxidation of the MXene surface, ${ }^{10}$ or insertion of metal ions. ${ }^{18-20}$ While these methods increased the MXene interlayer spacing, they have several drawbacks, including partial destruction of the MXene structure and poor control over the final interlayer distances. Additionally, the highest surface area achieved via these methods was $93.6 \mathrm{~m}^{2} \mathrm{~g}^{-1}$, lower than that of fully delaminated MXenes. ${ }^{10}$

In this work we investigate a novel pillaring approach for controlling the interlayer spacing and hence the properties of MXenes. Pillaring has been studied for several decades in heterogeneous catalysis, where it has been used to develop porous clays that act as catalyst supports. ${ }^{21}$ It involves the insertion of ionic or molecular species between clay layers, often utilising a pre-pillaring step, or a co-pillar, which aids the intercalation of the desired pillar. ${ }^{21}$ These techniques give a large degree of control over the final interlayer spacings and lead to high surface areas while maintaining the structural integrity of the starting material. Pillaring has been successfully applied to montmorillonite, ${ }^{21}$ kaolinite ${ }^{22}$ and titanosilicates, ${ }^{23}$ producing porous clays with surface areas as high as of $618 \mathrm{~m}^{2} \mathrm{~g}^{-1} .{ }^{23}$ Of particular interest are pillared titanosilicates, which have similar surface chemistries to titanium-based MXenes. ${ }^{23}$ There have been several reports on the intercalation of ionic surfactants ${ }^{24,25}$ and amines ${ }^{26,27}$ (common co-pillars in clays) into MXenes, which suggests that there is potential for applying pillaring techniques designed for clays to MXenes. Since many elements can act as pillars, this would create MXenes with a variety of interlayer spacings and different chemistries, adding a further element of control that can be used to tune MXenes for specific applications.

Recently, Luo et al. demonstrated the pillaring of $\mathrm{Ti}_{3} \mathrm{C}_{2}$ with cationic surfactants and tin chloride. ${ }^{24}$ They reported a large increase in the interlayer spacing to $2.7 \mathrm{~nm}$, and showed improved long term performance when the pillared material was tested in a lithium-ion battery. Here we investigate an alternative pillaring method based on $\mathrm{Si}$, which is a cheaper, lighter and more environmentally friendly element than $\mathrm{Sn}$. We report a $\mathrm{SiO}_{2}$-pillared $\mathrm{Ti}_{3} \mathrm{C}_{2}$ material, which was synthesised using amines (dodecylamine - DDA and octylamine - OA) as co-pillars with tetraethylortho silicate (TEOS) as the Si source. The amines and TEOS intercalate simultaneously, removing the need for a prepillaring step. A calcination step removes the amine template, allowing control of the interlayer spacing over a range of 0.75-3.2 nm.

The resulting pillared MXenes were then tested as anodes for $\mathrm{Na}$-ion batteries. Sodium-ion batteries are an emerging technology with several advantages over their lithium counterparts such as improved safety, sustainability and cost, owing to the high abundance of $\mathrm{Na}$. As such, they are considered ideal candidates for next-generation energy-storage applications. However, their commercialisation has been limited by a lack of appropriate electrode materials capable of accommodating the relatively large sodium ions over many cycles and at high rates ( $\mathrm{Na}^{+}$has an ionic radii of $1 \AA$ compared to $0.76 \AA$ for $\mathrm{Li}^{+}$). ${ }^{28}$ The large interlayer spacings afforded by our method hinted at increased performance for $\mathrm{Na}$-ion batteries, so our calcined porous MXene were tested as 
the negative electrode for a Na-ion battery. The pillared MXenes demonstrated significantly improved performance; showing superior capacity, rate capability and stability compared with the non-pillared sample. In addition, we investigated the intercalation mechanism, revealing how the functional groups can be tailored to optimise the pillaring process. This work demonstrates the applicability of pillaring strategies for MXenes, and is expected to drive further research on pillaring techniques and Si-MXene composites for a variety of applications.

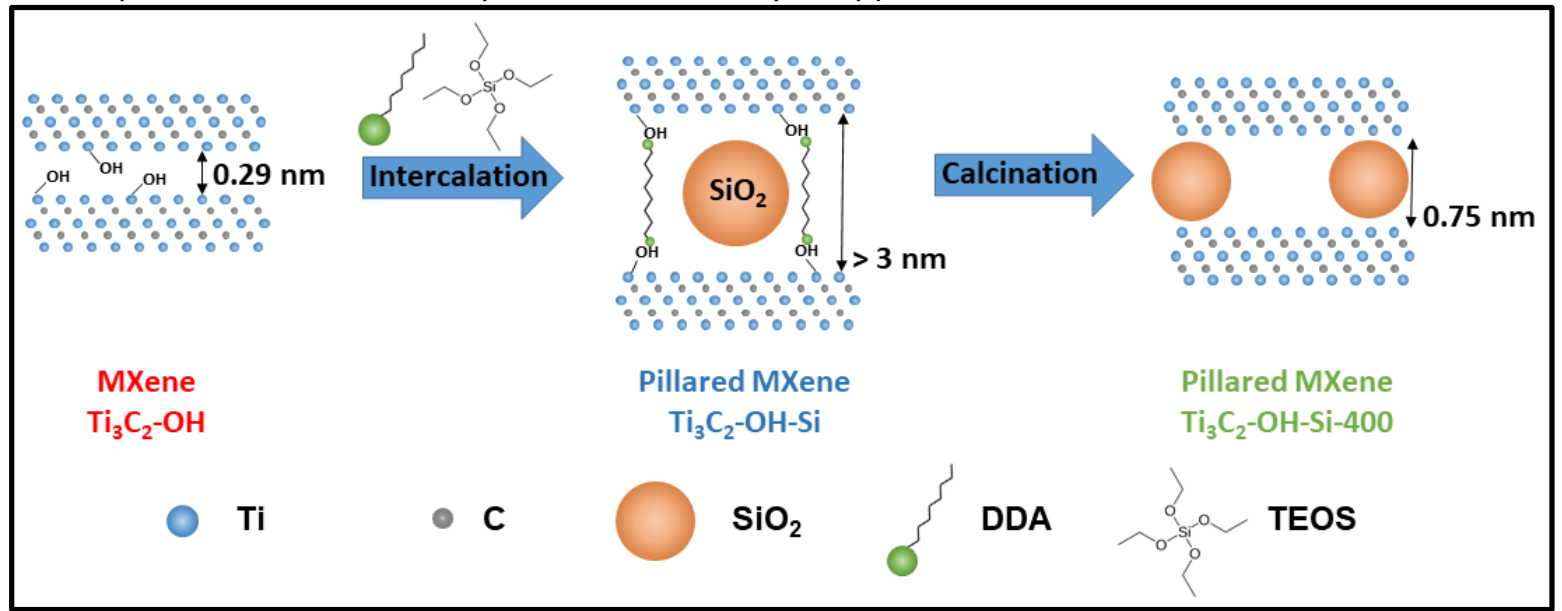

Figure 1. Schematic illustrating the pillaring process of MXenes.

Results and discussion Figure 1 is a summary schematic illustrating the process of synthesising the pillared MXenes. The MXenes were synthesised from $\mathrm{Ti}_{3} \mathrm{AlC}_{2} \mathrm{MAX}$ phase materials which were etched using a modified version of the $\mathrm{HCl}$ and fluoride salt-based method first reported by Ghidiu et al. ${ }^{2}$ The sample was washed with $\mathrm{HCl}$ to remove impurities and is referred to as $\mathrm{Ti}_{3} \mathrm{C}_{2}-\mathrm{OH}$. $\mathrm{The} \mathrm{Ti}_{3} \mathrm{C}_{2^{-}}$ $\mathrm{OH}$ MXene was then mixed with DDA and TEOS to intercalate Si between the $\mathrm{Ti}_{3} \mathrm{C}_{2}$ layers $\left(\mathrm{Ti}_{3} \mathrm{C}_{2}-\mathrm{OH}-\right.$ $\mathrm{Si})$. This was then calcined under argon at 300,400 or $500{ }^{\circ} \mathrm{C}$, which is shown by appending the calcination temperature onto the above sample names (e.g $\mathrm{Ti}_{3} \mathrm{C}_{2}-\mathrm{OH}-\mathrm{Si}-400$ refers to the $\mathrm{Ti}_{3} \mathrm{C}_{2}-\mathrm{OH}-\mathrm{Si}$ material after calcining at $400^{\circ} \mathrm{C}$ ). At each stage of the synthesis the materials were characterised by a variety of techniques (see the methods section for full synthesis and characterisation details).

Figure 2a shows that $\mathrm{Ti}_{3} \mathrm{C}_{2}$ was successfully etched from the sieved $\mathrm{Ti}_{3} \mathrm{AlC}_{2}$, with no MAX phase diffraction peaks remaining in the X-ray diffraction (XRD) plots. In particular, the (002) diffraction peak $^{29}$ has shifted to lower angles (from 9.5 to $6.8^{\circ} 2 \theta$ ), corresponding to the enlarged interlayer spacing in the MXene compared to the MAX phase. Scanning electron microscopy (SEM) shows the open layered morphology which is typical of MXenes (Figure 2b), ${ }^{1,2}$ and energy dispersive spectroscopy (EDS) results (Figure S1 in Supplementary Information) show no Al content, confirming complete etching of the Al layer. The EDS results also show only low levels of $\mathrm{F}(9 \mathrm{wt} . \%)$ and $\mathrm{Cl}(3$ wt.\%) in the sample, indicating that the majority of surface groups are -0 based terminations (17 wt.\%). 


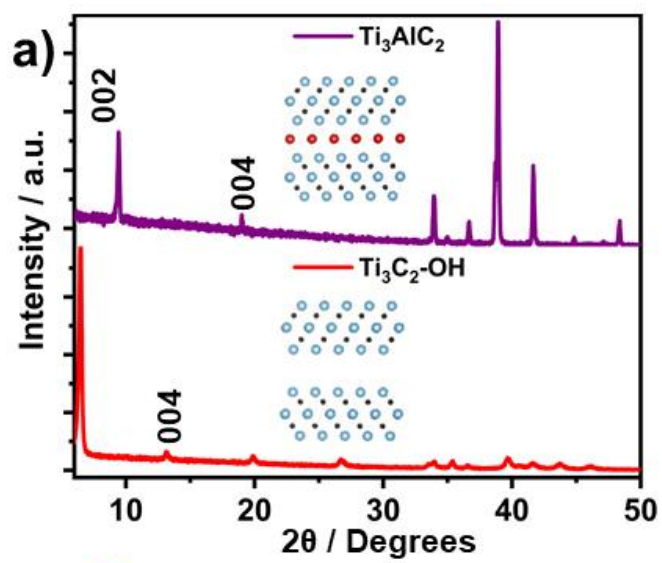

b)
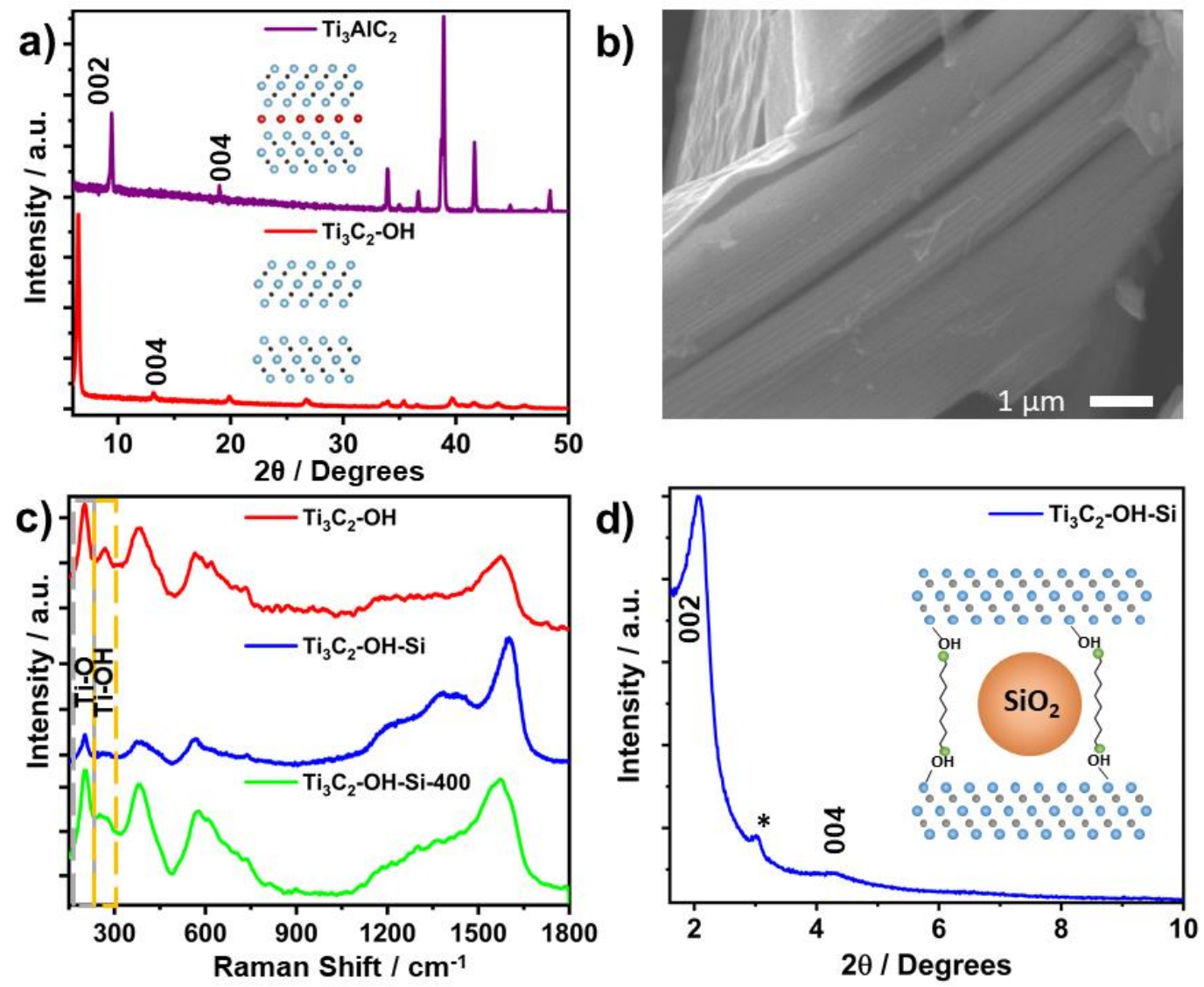

Figure 2. a) XRD patterns of the as made $\mathrm{Ti}_{3} \mathrm{AlC}_{2}, \mathrm{Ti}_{3} \mathrm{C}_{2}$ after $\mathrm{HCl}$ washing $\left(\mathrm{Ti}_{3} \mathrm{C}_{2}-\mathrm{OH}\right)$. The (002) and (004) diffraction peaks were indexed according to Peng et al. ${ }^{29}$ b) SEM micrograph of $\mathrm{Ti}_{3} \mathrm{C}_{2} \mathrm{c}$ ) Raman spectra of the acid treated MXene (red, $\mathrm{Ti}_{3} \mathrm{C}_{2}-\mathrm{OH}$ ), and the intercalated (blue, $\mathrm{Ti}_{3} \mathrm{C}_{2}-\mathrm{OH}-\mathrm{Si}$ ) and calcined at $400{ }^{\circ} \mathrm{C}$ (green, $\mathrm{Ti}_{3} \mathrm{C}_{2}-\mathrm{Si}-400$ ) pillared $\mathrm{MXene}$, with dashed lines highlighting the key peaks corresponding to Ti-O (grey) and $\mathrm{Ti}-\mathrm{OH}$ (orange) functional groups and d) Low angle XRD of the MXene after intercalation $\left(\mathrm{Ti}_{3} \mathrm{C}_{2}-\mathrm{OH}-\mathrm{Si}\right)$. The asterisk highlights a peak corresponding to the glass sample holder (see SI Figure S9 for sample holder reference spectra).

Raman spectroscopy has previously been used to study $-\mathrm{OH}$ and $-\mathrm{O}$ terminations of $\mathrm{Ti}_{3} \mathrm{C}_{2}$, as these are not easily distinguished using other techniques. ${ }^{30}$ Figure $2 \mathrm{c}$ shows the Raman spectra for the acid washed $\mathrm{MXene}\left(\mathrm{Ti}_{3} \mathrm{C}_{2}-\mathrm{OH}\right)$, and for the pillared $\left(\mathrm{Ti}_{3} \mathrm{C}_{2}-\mathrm{OH}-\mathrm{Si}\right)$ and calcined samples $\left(\mathrm{Ti}_{3} \mathrm{C}_{2}-\mathrm{OH}-\mathrm{Si}-400\right)$. $\mathrm{Ti}_{3} \mathrm{C}_{2}-\mathrm{OH}$ shows a sharp peak at $207 \mathrm{~cm}^{-1}$, corresponding to the presence of Ti-O terminations and a smaller peak at around $270 \mathrm{~cm}^{-1}$ reveals the presence of Ti-OH groups in the sample. ${ }^{30,31}$ The other peaks present up to $1,000 \mathrm{~cm}^{-1}$ are known to be formed by the overlap of Ti-X vibrations (where $\mathrm{X}$ is any of the known termination groups) and are therefore not relevant for the study of the surface chemistry. ${ }^{30}$ The broad peak at around $1,570 \mathrm{~cm}^{-1}$ shows that there is a small amount of amorphous carbon present in the treated MXenes, suggesting slight over-etching of the MAX phase precursor. 


\section{DDA-TEOS Pillaring}

$\mathrm{Ti}_{3} \mathrm{C}_{2}-\mathrm{OH}$ was treated using DDA and TEOS in order to expand the MXene layers. After treatment, three new broad Raman peaks appear between 1,100-1,700 $\mathrm{cm}^{-1}$ corresponding to the presence of DDA and TEOS hydrolysis products (Figure $2 \mathrm{c}$ ). There is also a large increase in carbon content observed in the STEM-EDS (Figure S2a) and the presence of $\mathrm{C}-\mathrm{H}$ bonds are confirmed by IR spectroscopy (Figure S3). Taken together, these results confirm the successful co-intercalation of DDA and TEOS into the acid treated $\mathrm{Ti}_{3} \mathrm{C}_{2}$. When $\mathrm{Ti}_{3} \mathrm{C}_{2}$ is dispersed in just TEOS, there is no sign of intercalation (Figure S4).

Figure $2 \mathrm{~d}$ shows a clear diffraction peak at $2.1^{\circ} 2 \theta$ corresponding to the (002) reflection of the MXene, with a large $d$-spacing of $4.2 \mathrm{~nm}$. In addition, a small broad peak at $4.2^{\circ} 2 \theta$ indexes to the (004) diffraction peak, with an expanded d-spacing of $2.1 \mathrm{~nm}$. It has previously been reported that the thickness of a single $\mathrm{Ti}_{3} \mathrm{C}_{2}$ sheet is $0.95 \mathrm{~nm},{ }^{24}$ which gives a gallery height of $3.25 \mathrm{~nm}$ for the pillared MXene, around 10 times that of the starting MXene; a clear sign of successful pillaring.
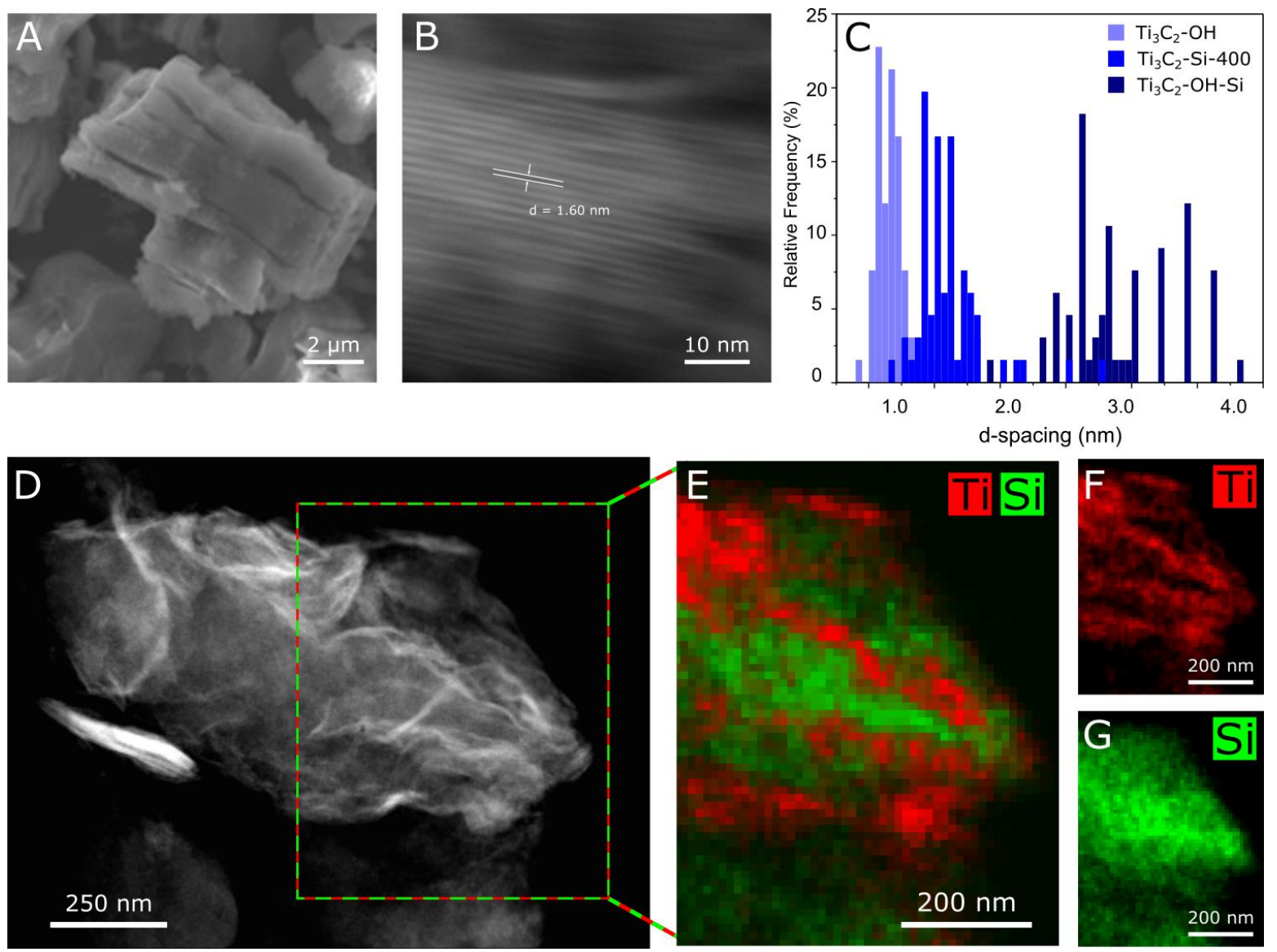

Figure 3. SEM and STEM Characterisation of the pillared MXene. a) SEM micrograph of the intercalated MXene ( $\left.\mathrm{Ti}_{3} \mathrm{C}_{2}-\mathrm{OH}-\mathrm{Si}\right)$ b) STEM cross sectional image of atomic planes of $\mathrm{Ti}_{3} \mathrm{C}_{2}-\mathrm{OH}-\mathrm{Si}-400$, with an example d-spacing labelled. c) Graph showing the results of the 002 interlayer distances measured using STEM. $d$-g) STEM-EDS mapping of the pillared sample post calcination $\left(\mathrm{Ti}_{3} \mathrm{C}_{2}-\mathrm{OH}-\mathrm{Si}\right.$ 400).

Scanning transmission electron microscopy (STEM) analysis (Figure 3) also confirms the large increase in interlayer (002) d-spacing, from an average of around $1 \mathrm{~nm}$ in the non-pillared MXene to $2.7 \mathrm{~nm}$ after pillaring (Figure $3 \mathrm{~b}-\mathrm{c}$ ). This is slightly less than the spacing calculated by XRD, perhaps 
due to electron beam induced specimen damage or the movement / partial removal of the intercalated molecules within the TEM vacuum. This explanation is supported by the observation that after calcination, when the intercalated molecules are removed, there is little difference the interlayer spacings calculated by XRD (Figure 4a) or STEM (Figure 3c). Differences may also result from the sampling volumes between the two methods - XRD is a bulk method, whereas the STEM measurements are highly localised. The STEM measurements suggest that the standard deviation of interlayer distances increases with pillaring compared to the non-pillared MXene, suggesting that the pillars have local variations in height or concentration across the sample. To the authors' knowledge, this is the largest interlayer distance reported for a MXene and one of the largest for any 2D material, which are rarely above $2 \mathrm{~nm} \cdot{ }^{32-40}$ A summary of the highest previously reported interlayer spacings can be found in Table S1 and is illustrated in Figure 4c. This includes alkali metal cation pillars, ${ }^{41}$ organic molecules, ${ }^{42}$ carbon nanotubes (CNTs) grafted with ionic surfactants, ${ }^{43}$ cationic surfactant $\mathrm{CTAB}$ and $\mathrm{Sn}^{2+},{ }^{44}$ cationic surfactants and $\mathrm{Sn}^{4+},{ }^{45}$ and pyrolyised amines. ${ }^{46}$ It can be clearly seen that our pillaring method achieves significantly larger interlayer spacings with control over a wider range than previously reported methods.

STEM-EDS elemental mapping results (Figure S2a) confirm that this increase in interlayer spacing is correlated with the presence of $\mathrm{Si}$ in the sample (3.1 wt.\%), although neither TEM or SEM characterisation shows any sign of $\mathrm{SiO}_{2}$ particles external to the MXene (Figures $3 a$ and $\mathrm{S} 2 \mathrm{~b}$ ).

To produce a stable pillared MXene, the calcination treatment should retain the ordered MXene structure but remove residual molecular templates (DDA and TEOS). After calcination at 300 or 400 ${ }^{\circ} \mathrm{C}$, the (002) diffraction peak broadens and shifts to higher angles, suggesting a shrinkage of the interlayer spacings (Figure 4). Calcination at $300{ }^{\circ} \mathrm{C}$ produces a (002) diffraction peak at $4^{\circ} 2 \theta$ corresponding to an interlayer spacing of $2.2 \mathrm{~nm}$, while calcination at $400{ }^{\circ} \mathrm{C}$ gives a (002) peak at 5.2 degrees corresponding to an interlayer spacing of $1.7 \mathrm{~nm}$. The reduction in interlayer separation of the $\mathrm{Ti}_{3} \mathrm{C}_{2}-\mathrm{OH}-\mathrm{Si}-400$ sample was also measured by STEM, providing excellent agreement with the XRD data. This shows that our pillaring method can be used to create MXene materials with a range of interlayer spacings, which are summarised in Table S2. After calcining at $500{ }^{\circ} \mathrm{C}$, the $(002)$ diffraction peak is no longer visible, suggesting an unwanted loss of the ordered pillared structure. It should be noted that the XRD analysis showed that the (002) diffraction peak broadened slightly after calcination (Figure 4a), suggesting a larger variation in the interlayer spacings. This is likely to result from local variations due to slightly inhomogeneous distribution of the pillars through the interlayer. For example, the interlayer spacing is likely to be slightly decreased at areas between the pillars compared to where the MXene sheets are in direct contact with the pillars. This is supported by the STEM studies (Figure 3c), which also found slight variations in the interlayer distances post calcination. 

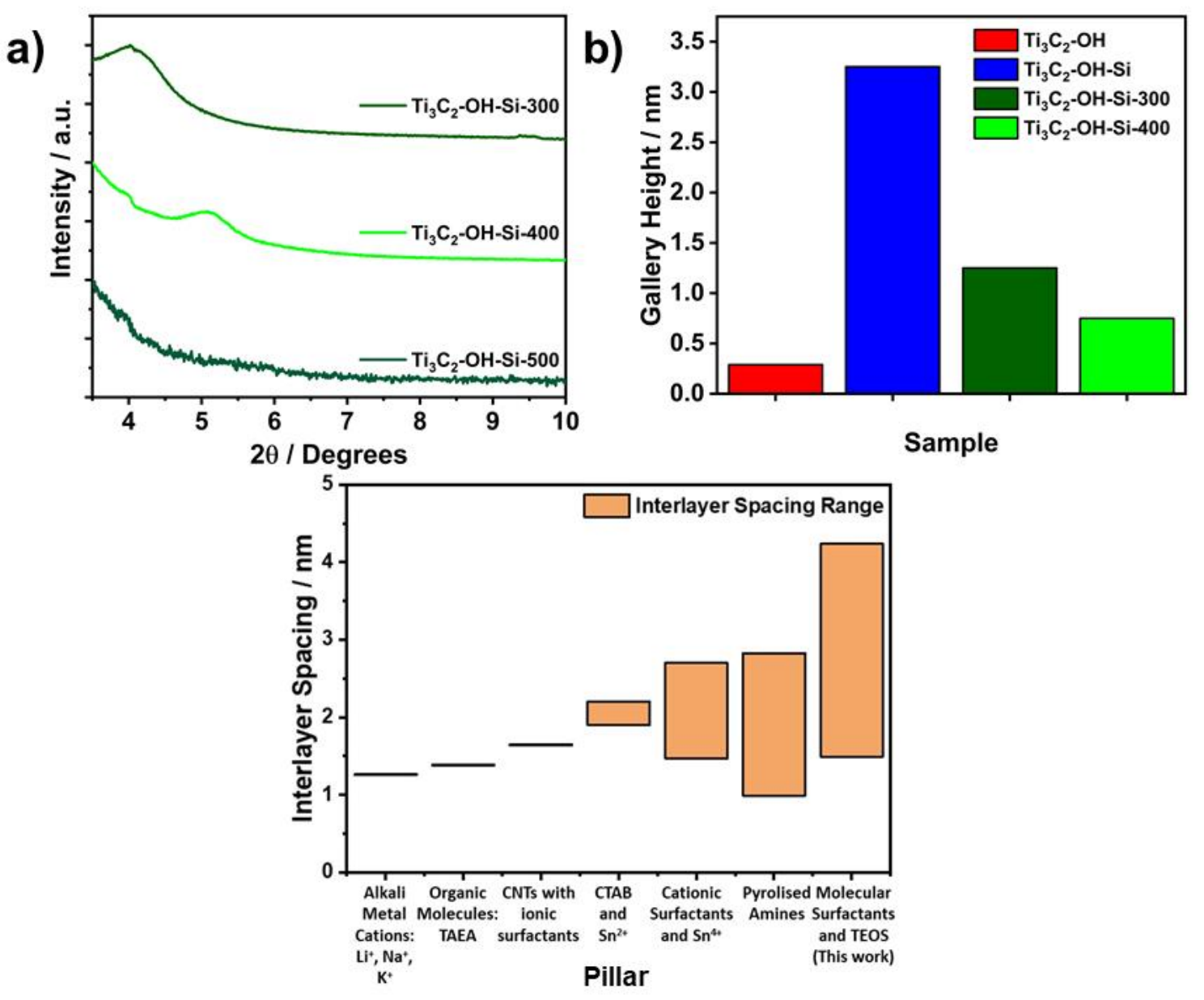

Figure 4. Effect of calcination temperature on interlayer spacing and gallery height. a) XRD patterns tracking the (002) diffraction peak after different calcination temperatures $\left(300,400\right.$ and $\left.500{ }^{\circ} \mathrm{C}\right)$. b) Chart showing the range of gallery heights achieved using the reported pillaring method. c) Comparison of interlayer spacings achieved in this work with other pillaring reports.

TGA analysis of the intercalated $\mathrm{Ti}_{3} \mathrm{C}_{2}$ shows mass loss starting at $360{ }^{\circ} \mathrm{C}$ which increases rapidly above $400{ }^{\circ} \mathrm{C}$ (Figure S5). The SEM-EDS results for the sample calcined at $400{ }^{\circ} \mathrm{C}$ (Figure S6) show that the carbon content is decreased after calcination (12.1 wt.\% after calcination compared to 33.0 wt.\% before calcination). Both results suggest the removal of the DDA template after calcining at 400 ${ }^{\circ} \mathrm{C}$ or above. The decomposition and removal of the amine is further confirmed by the broadening and decrease in intensity of peaks between $1,100-1,700 \mathrm{~cm}^{-1}$ in the Raman spectrum (Figure 2c) and the loss of $\mathrm{C}-\mathrm{H}$ vibrations in the IR spectrum (Figure S7).

STEM-EDS maps (Figure 3) confirm the nanoscale layered nature of $\mathrm{Ti}$ and $\mathrm{Si}$ in the $400{ }^{\circ} \mathrm{C}$ calcined sample $\left(\mathrm{Ti}_{3} \mathrm{C}_{2}-\mathrm{OH}-\mathrm{Si}-400\right)$ is retained after the heat treatment, with alternating bands of $\mathrm{Ti}$ and $\mathrm{Si}$ clearly visible. This matches STEM-EDS maps previously reported for MXene pillaring. ${ }^{24,41}$ Importantly, neither XRD (Figure S8) nor Raman (Figure 2c) results show peaks relating to $\mathrm{TiO}_{2}$, showing that the MXene was not oxidised during calcination. Therefore, calcination at $400{ }^{\circ} \mathrm{C}\left(\mathrm{Ti}_{3} \mathrm{C}_{2^{-}}\right.$ $\mathrm{OH}-\mathrm{Si}-400)$ was taken as the optimum temperature due to retaining the ordered structure while maximising removal of the molecular templates and this sample has been used for further characterisation.

To study the effect of the pillaring process on the surface area and porosity of the MXene in more detail, $\mathrm{N}_{2}$ adsorption-desorption experiments were carried out for all stages of synthesis (Figure 5). 
BET analysis on the nitrogen isotherms shows a large increase in the surface area, from $4 \mathrm{~m}^{2} \mathrm{~g}^{-1}$ after acid treatment, $\mathrm{Ti}_{3} \mathrm{C}_{2}-\mathrm{OH}$, to $235 \mathrm{~m}^{2} \mathrm{~g}^{-1}$ after intercalation, $\mathrm{Ti}_{3} \mathrm{C}_{2}$ - $\mathrm{OH}$-Si (almost a 60 -fold increase). This is comparable to, and in many cases superior to, that of many pillared graphene-based materials, which have typically reported specific surface areas between 130 and $330 \mathrm{~m}^{2} \mathrm{~g}^{-1}$, and pillared $\mathrm{MoS}_{2}\left(186 \mathrm{~m}^{2} \mathrm{~g}^{-1}\right) \cdot{ }^{36,38-40,47}$ Inset in Figure 5a-d are the corresponding the average pore widths predicted from Non-Local Density Functional Theory (NL DFT) calculations where the pore dimensions were found to increase from $0.82 \mathrm{~nm}$ to $3 \mathrm{~nm}$ after intercalation. These values are consistent with the BET pores being the interlayer gallery regions. To our knowledge, this is the highest surface area reported for an MXene using an intercalation-based pillaring method and demonstrates the creation of a new porous material. The only comparable surface area for MXene based materials was $290 \mathrm{~m}^{2} \mathrm{~g}^{-1}$, which was achieved by engineering a 3D structure via freeze drying of MXenes. ${ }^{48}$
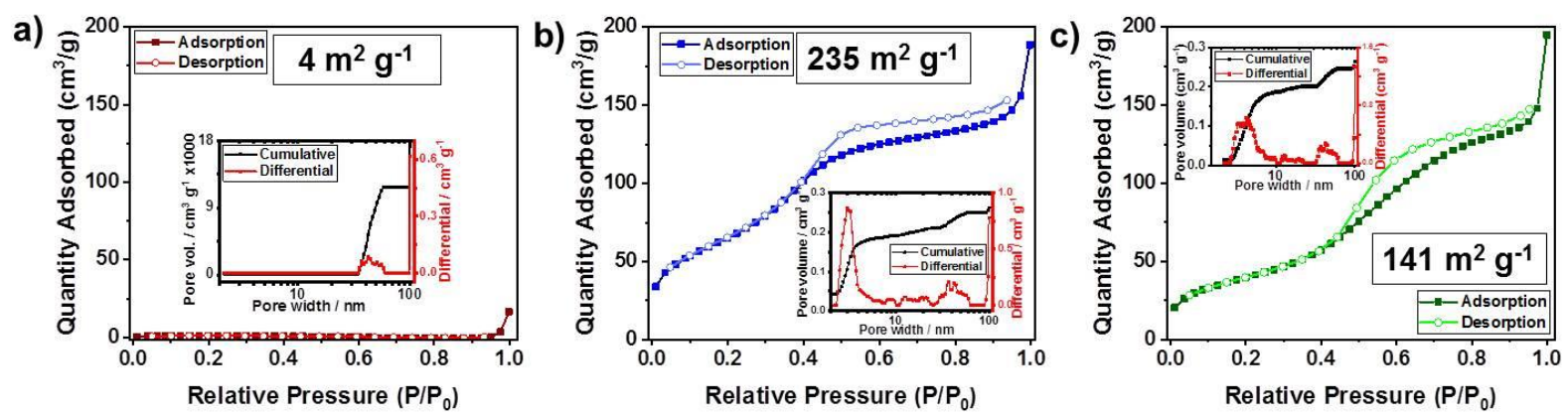

Figure 5. Adsorption isotherms from $\mathrm{N}_{2}$ adsorption-desorption experiments. The BET surface area is also given in each panel. a) $\mathrm{Ti}_{3} \mathrm{C}_{2}-\mathrm{OH}$, b) $\mathrm{Ti}_{3} \mathrm{C}_{2}-\mathrm{OH}-\mathrm{Si}$, and c) $\mathrm{Ti}_{3} \mathrm{C}_{2}-\mathrm{OH}-\mathrm{Si}-400$. Insets: Pore size distributions derived from the NL DFT method for each sample.

Interestingly, the adsorption isotherms for the pillared $\mathrm{Ti}_{3} \mathrm{C}_{2}-\mathrm{OH}-\mathrm{Si}$, and pillared + calcined $\mathrm{Ti}_{3} \mathrm{C}_{2}-\mathrm{OH}$ Si-400 materials (Figure $5 c$ and d) (Type II according to the IUPAC classification guide) ${ }^{49}$ match those found in $\mathrm{N}_{2}$ adsorption studies of freeze-dried MXenes, with a small, but significant, hysteresis observed above $0.5 \mathrm{P} / \mathrm{P}_{0}$ partial pressures. ${ }^{48}$. However, unlike the report on freeze-dried MXenes, we observed only minimal formation of larger mesopores above $10 \mathrm{~nm}$ in diameter, suggesting that the increase in surface area is mostly due to the expansion of the interlayer of multistacked $\mathrm{Ti}_{3} \mathrm{C}_{2}$, by the incorporation of pillars, and not the delamination and re-stacking of nanosheets. This methodology also leads to a much more uniform pore size than those obtained in the freeze-dried MXene, as can be observed in Figure 5. We note that 3D structuring methods could be combined with our pillaring approach, and could potentially create even larger surface area MXene materials, with hierarchically ordered architectures.

BET surface area measurements on the calcined sample show a decrease in surface area from 235 $\mathrm{m}^{2} \mathrm{~g}^{-1}$ in the pre-calcination material to $141 \mathrm{~m}^{2} \mathrm{~g}^{-1}$ in $\mathrm{Ti}_{3} \mathrm{C}_{2}-\mathrm{OH}-\mathrm{Si}-400$ (Figure 5), with an average pore width of around $4 \mathrm{~nm}$, and a wider pore size distribution than that observed before calcination. This overall decrease in surface area is consistent with the XRD, Raman and IR characterisation, and is likely due to the removal of the DDA template. The wider pore size distribution is also consistent with the XRD results (Figure 4), where the (002) diffraction peak broadens after calcination, suggesting a wider range of interlayer distances. However, the XRD results do not cover the region that would detect a $4 \mathrm{~nm}$ pore ( $d$-spacing $\sim 5 \mathrm{~nm}$ hence $2 \theta<1.5^{\circ}$ ), so cannot show this increase. The XRD does show a (002) peak at around $1.75 \mathrm{~nm}$ d-spacing, consistent with TEM, which suggests the 4 $\mathrm{nm}$ pores may be caused by restacking of the sheets rather than interlayer spacings. Importantly the surface area of the calcined $\mathrm{Ti}_{3} \mathrm{C}_{2}-\mathrm{OH}-\mathrm{Si}-400$ material is still $\sim 30$ times larger than the initial MXene, 
confirming that the post-calcination MXene maintains its porosity and consists of well-defined pores between the $\mathrm{Ti}_{3} \mathrm{C}_{2}$ nanosheets and the $\mathrm{SiO}_{2}$ pillars. The adsorption measurements were carried out 10 months after synthesis of the pillared materials, confirming the long-term stability of these materials.

\section{Intercalation Mechanism}

Having confirmed successful intercalation, we now focus on understanding the intercalation and pillaring mechanism occurring during the pillaring process. Raman spectroscopy (Figure 2c), shows that the Ti-OH peak $\left(270 \mathrm{~cm}^{-1}\right)$ has broadened to between $220 \mathrm{~cm}^{-1}$ and $300 \mathrm{~cm}^{-1}$, shifted to slightly lower wavenumbers and lowered significantly in intensity in both the intercalated $\left(\mathrm{Ti}_{3} \mathrm{C}_{2}-\mathrm{OH}-\mathrm{Si}\right)$ and calcined $\left(\mathrm{Ti}_{3} \mathrm{C}_{2}-\mathrm{OH}-\mathrm{Si}-400\right)$ materials compared to the $\mathrm{Ti}_{3} \mathrm{C}_{2}-\mathrm{OH}$ material. This implies that the $-\mathrm{OH}$ surface groups are directly involved in the pillared process. In addition, there is no change in the vibrations linked to Ti-O $\left(205 \mathrm{~cm}^{-1}\right)$ upon intercalation, suggesting the $-O$ functional groups are inactive. To investigate the effect of the two surface groups in more detail, an alkali wash (1 M $\mathrm{NaOH}$ ) was used to remove all $-\mathrm{OH}$ terminations, leaving majority $-\mathrm{O}$ groups (denoted $\mathrm{Ti}_{3} \mathrm{C}_{2}-\mathrm{O}$ ). The same pillaring procedure was then applied to this sample. Interestingly, the XRD pattern for the alkali treated material was identical to the sample holder at low angles, with no low angle (002) diffraction peak corresponding to a pillared MXene (Figure S9). This further implies that the $-\mathrm{OH}$ groups play an important role in facilitating the pillaring process.

Solid-state nuclear magnetic resonance (NMR) was used to gain further information on the surface functional groups and pillaring species present in the MXene samples (Figure 6). There are three main $\mathrm{H}$ environments expected for the protons in the MXene samples ( $\mathrm{Ti}-\mathrm{OH}, \mathrm{H}_{2} \mathrm{O}$, and amine). The ${ }^{1} \mathrm{H}$ spectra for the four samples are different (Figure 6a), indicating differences in surface species, water content, and $\mathrm{H}$-bonding. The ${ }^{1} \mathrm{H}$ spectrum for $\mathrm{Ti}_{3} \mathrm{C}_{2}-\mathrm{O}$ is dominated by a peak at $4.2 \mathrm{ppm}$, which can be assigned to water present in the sample. A similar peak is observed in the calcinedpillared sample $\left(\mathrm{Ti}_{3} \mathrm{C}_{2}-\mathrm{OH}-\mathrm{Si}-400\right)$, but is absent in the ${ }^{1} \mathrm{H}$ spectra for $\mathrm{Ti}_{3} \mathrm{C}_{2}-\mathrm{OH}$ and $\mathrm{Ti}_{3} \mathrm{C}_{2}-\mathrm{OH}-\mathrm{Si}$. The ${ }^{1} \mathrm{H}$ spectrum for $\mathrm{Ti}_{3} \mathrm{C}_{2}-\mathrm{OH}$ has broad peaks at 13 and $7 \mathrm{ppm}$; the former can be assigned to $\mathrm{Ti}^{-O H},{ }^{50}$ and is not observed in the ${ }^{1} \mathrm{H}$ spectra for the pillared materials, supporting the Raman results (Figure $2 \mathrm{c}$ ). The broad peaks around 7-9 ppm in the samples may correspond to $\mathrm{Ti}-\mathrm{OH}$ and/or water, with different $\mathrm{H}$-bonding to those discussed above. This, combined with the Raman spectroscopy results, provides strong evidence of the - $\mathrm{OH}$ terminations being active in the bonding between the amine copillar and the MXene. The absence of a peak corresponding to Ti-OH in the alkali-treated sample $\left(\mathrm{Ti}_{3} \mathrm{C}_{2}-\mathrm{O}\right)$, is consistent with the Raman spectra (Figure $2 \mathrm{c}$ ). There are additional peaks between $0-2$ $\mathrm{ppm}$, which are as yet unidentified and considered negligible in the literature ${ }^{50}$ and so are assumed not to play a significant role in this work. In addition, the $\mathrm{Ti}_{3} \mathrm{C}_{2}-\mathrm{OH}-\mathrm{Si}$ sample shows sharp peaks corresponding to the DDA, further confirming that this is present in the sample. 

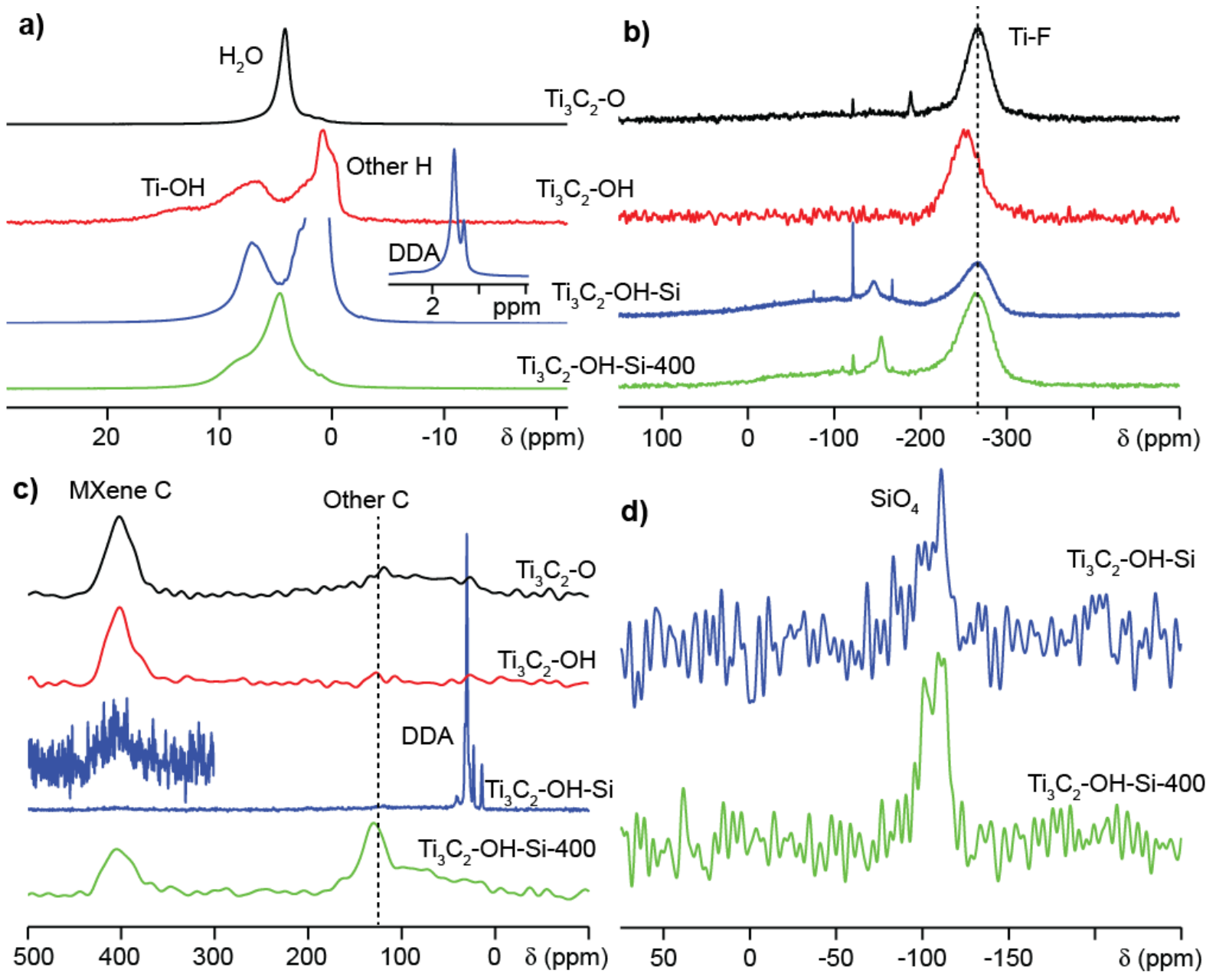

Figure 6. Solid-state NMR spectra (16.4 T, 29-30 kHz Magic Angle Spinning (MAS)) of $\mathrm{Ti}_{3} \mathrm{C}_{2}-\mathrm{O}, \mathrm{Ti}_{3} \mathrm{C}_{2}-$ $\mathrm{OH}, \mathrm{Ti}_{3} \mathrm{C}_{2}-\mathrm{OH}-\mathrm{Si}$ and $\mathrm{Ti}_{3} \mathrm{C}_{2}-\mathrm{OH}-\mathrm{Si}-400$. a) ${ }^{1} \mathrm{H}$ MAS NMR spectra, where the inset shows the DDA peaks at full intensity, b) ${ }^{19} \mathrm{~F}$ MAS NMR spectra, c) ${ }^{13} \mathrm{C}$ MAS NMR spectra, where the inset in $\mathrm{Ti}_{3} \mathrm{C}_{2}-\mathrm{OH}-\mathrm{Si}$ is a magnification of the MXene $C$ peak, and d) ${ }^{29}$ Si MAS NMR spectra of the Si-containing samples.

After calcination, a peak corresponding to interlayer water appears at $4.7 \mathrm{ppm}$, which was not present in $\mathrm{Ti}_{3} \mathrm{C}_{2}-\mathrm{OH}-\mathrm{Si}$ (pre-calcination). This implies the adsorption of water from the atmosphere occurs between the calcination and the measurement, (the time between calcination and the NMR measurements was around 3 months), since the calcination was done under an argon atmosphere, and the high temperatures would not be compatible with additional water accumulating between the sheets. Both the pre- and post-calcination samples were stored in the same conditions for the same time, which suggests that the DDA repels any atmospheric water encountered during this time. It is possible, due to the hydrophobic nature of the DDA, that during the pillaring process, the DDA repels water molecules as it intercalates between the layers, and any remaining water molecules react with the TEOS to form the $\mathrm{SiO}_{2}$ hydrolysis product. Once the hydrolysis reaction is complete, no further water enters the interlayer due to repulsion by the DDA. The use of hydrophobic intercalants to keep the interlayer free of water could be important for applications where water would be harmful to performance. It is also possible that the ${ }^{1} \mathrm{H}$ NMR signal from the amine, which has very high intensity, is masking the signal corresponding to the interlayer water. Importantly, the post-calcination material $\left(\mathrm{Ti}_{3} \mathrm{C}_{2}-\mathrm{OH}-\mathrm{Si}-400\right)$ shows that water can re-enter the interlayer after the amine has decomposed, suggesting that the MXene surface has been returned to its original hydrophilic state. 
The ${ }^{19} \mathrm{~F}$ NMR spectra (Figure $6 \mathrm{~b}$ ) shows a main peak centred around $-275 \mathrm{ppm}$ for most of the samples, but which is shifted for the $\mathrm{Ti}_{3} \mathrm{C}_{2}-\mathrm{OH}$ sample and is assigned to $-\mathrm{F}$ terminations. It is noted that there were challenges in spinning the $\mathrm{Ti}_{3} \mathrm{C}_{2}-\mathrm{OH}$ sample, indicating some difference in behaviour of this sample. Generally, the similar shift for the other samples suggests that the $-F$ surface groups are inactive with respect to the pillaring process, further emphasising the importance of -OH groups and surface chemistry in general for the intercalating and pillaring of MXenes. This also suggests that the amount of $\mathrm{Si}$ intercalated may be tuneable by carefully controlling the amounts of $-\mathrm{F},-\mathrm{O}$ and $\mathrm{OH}$ groups. The ${ }^{19} \mathrm{~F} N \mathrm{NR}$ also shows the presence of $\mathrm{F}$-containing impurities, likely to be from the etching process, as have been reported in other studies. ${ }^{3,50}$

The ${ }^{13} \mathrm{C}$ NMR spectra (Figure 6c) shows the $\mathrm{C}$ layer in the MXene with a broad peak at $400 \mathrm{ppm}$, which is consistent with the results from Hope et al. ${ }^{50}$ and also confirms the presence of DDA in the corresponding sample with peaks between 20-50 ppm (note that the spectrum for the ${ }^{13} \mathrm{C}$ NMR for the $\mathrm{Ti}_{3} \mathrm{C}_{2}-\mathrm{OH}-\mathrm{Si}$ sample appears particularly noisy due to the high intensity of the DDA signals). A peak at around $125 \mathrm{ppm}$ can be distinguished from the background C (0-200 ppm), this corresponds to the amorphous graphitic $\mathrm{C}$ as observed in the Raman (Figure $2 \mathrm{c}$ ) and EDS (Figure $\mathrm{S6}$ ). It is possible that this carbon content could help improve the electrical conductivity of the pillared MXene, which is particularly important for high rate electrochemical applications. ${ }^{51,52}$ The ${ }^{29} \mathrm{Si}$ NMR spectra (Figure 6d) show that there are tetrahedral $\mathrm{Si}$ environments $\left(\mathrm{SiO}_{4}\right)$ in the samples, with a broad peak between -100 and -120 ppm, ${ }^{8}$ confirming the successful DDA-catalysed hydrolysis of TEOS to silica, revealing $\mathrm{SiO}_{2}$ as the final pillar.

Overall, these results suggest the intercalation mechanism relies directly on the $\mathrm{Ti}-\mathrm{OH}$ termination groups. The $-\mathrm{OH}$ groups hydrogen-bond to the $\mathrm{N}-\mathrm{H}$ groups of the amine (DDA), which intercalates between the MXene layers with the TEOS solvent, thus allowing the pillaring of the MXene with Sibased pillars. Neither the $-\mathrm{F}$ or $-\mathrm{O}$ are active towards the intercalation and hydrolysis process, which is accompanied by the removal of water molecules from the interlayer. Upon calcination, the DDA templates are decomposed and largely removed from the pillared MXene, giving a highly porous material.

Interestingly, other amines also assist the intercalation of TEOS into $\mathrm{Ti}_{3} \mathrm{C}_{2}$, as shown by the XRD of $\mathrm{Ti}_{3} \mathrm{C}_{2}-\mathrm{OH}$ intercalated with just octylamine and with octylamine and TEOS in Figure S10. Importantly, this gives a different interlayer spacing, showing the potential for this technique to give a range of pore sizes. The spacing achieved here is larger than those achieved by cationic surfactant pillaring of molecules of the same chain size. ${ }^{24}$ This shows that the orientation of the molecules in the interlayer is very different, with cationic surfactants thought to lay at an angle of around 30 degrees, ${ }^{24}$ whereas these amines are clearly more vertically aligned. In fact, DDA in clay pillaring is thought to form bilayers in the interlayer, giving gallery heights of 2 times that of the chain length. ${ }^{23,53}$ This is important for future work on the pillaring of MXenes, since it shows that consideration of the chain size of the pillar alone is not enough, as the interactions between the pillaring molecules and MXene surface groups must be well understood for controlled pillaring. 


\section{Electrochemical performance in Na-ion batteries}
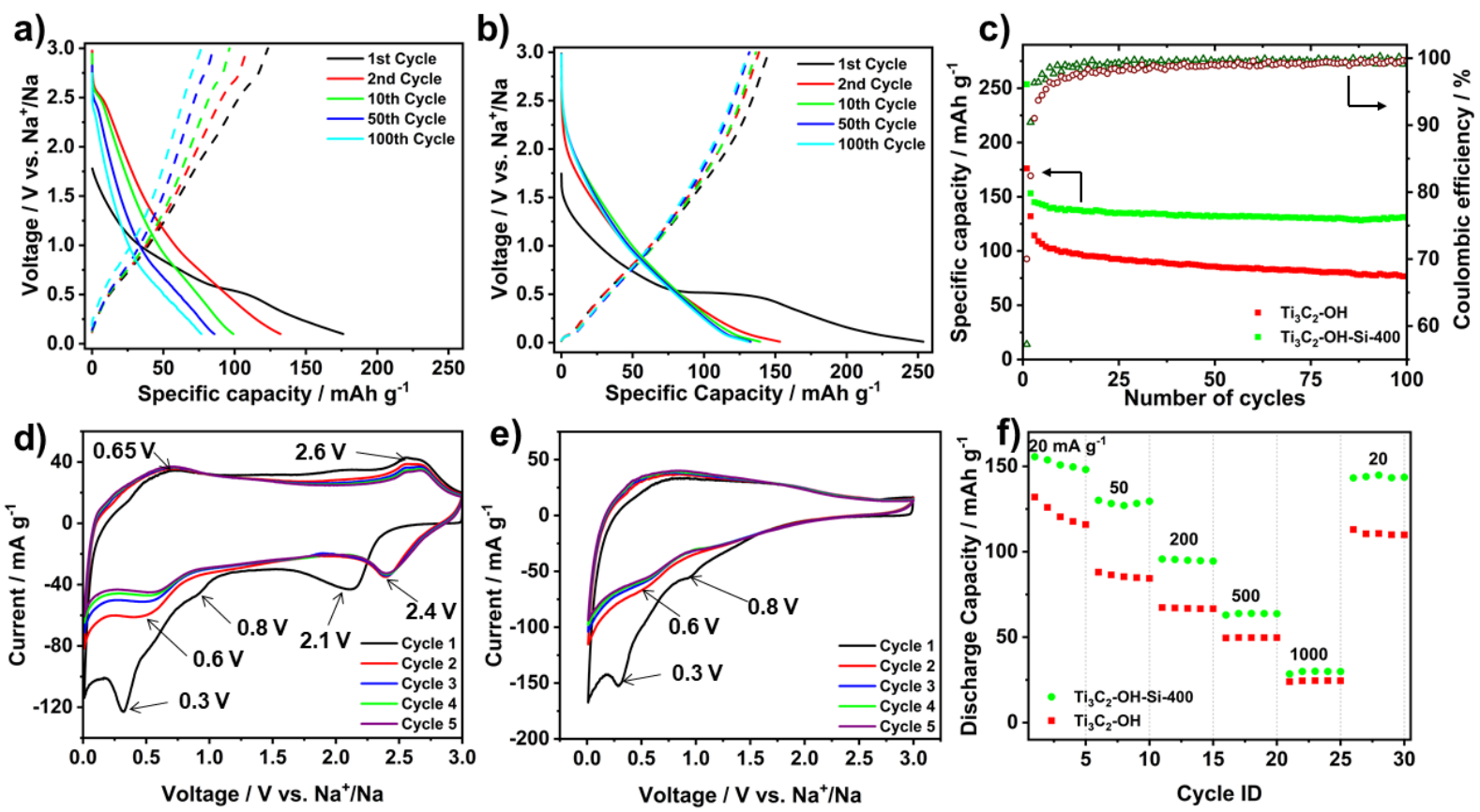

Figure 7. a-c) Galvanostatic data from half-cell tests against Na metal at $20 \mathrm{~mA} \mathrm{~g}^{-1}$ in the voltage range 0.01-3 V. a) Load curves for selected cycles for a) $\mathrm{Ti}_{3} \mathrm{C}_{2}-\mathrm{OH}$ and b) $\mathrm{Ti}_{3} \mathrm{C}_{2}-\mathrm{OH}-\mathrm{Si}-400$, c) Coulombic efficiency and discharge capacities of the pillared and non-pillared samples over 100 cycles. $d$ and e) Cyclic voltammograms at 0.01-3 V vs. Na metal at a scan rate of $0.2 \mathrm{mV} \mathrm{s}^{-1}$ for d) the non-pillared, $\mathrm{Ti}_{3} \mathrm{C}_{2}-\mathrm{OH}$ and e) pillared $\mathrm{MXene}, \mathrm{Ti}_{3} \mathrm{C}_{2}-\mathrm{OH}-\mathrm{Si}-400$. f) Rate capability tests for the pillared and non-pillared MXene at rates of 20,50,200, 500 and 1,000 mA g ${ }^{-1}$. Five cycles are shown for each rate (one additional cycle at $20 \mathrm{~mA} \mathrm{~g}^{-1}$ was conducted to ensure SEI formation).

To investigate the effect of the pillaring process on the electrochemical performance, the pillared and non-pillared materials were tested against $\mathrm{Na}$ as both a counter and reference electrode in the voltage range of $0.01-3 \mathrm{~V}$ for 100 cycles at $20 \mathrm{~mA} \mathrm{~g}^{-1}$. Figure $7 \mathrm{a}$, and $\mathrm{b}$ shows the load curves for the non-pillared and pillared MXenes, $\mathrm{Ti}_{3} \mathrm{C}_{2}-\mathrm{OH}$ and $\mathrm{Ti}_{3} \mathrm{C}_{2}-\mathrm{OH}-\mathrm{Si}-400$, respectively. The pillared material shows a higher capacity on the second cycle (156 mAh g-1 compared to $132 \mathrm{mAh} \mathrm{g}^{-1}$ for the non-pillared material) and significantly better cycling stability. By the $100^{\text {th }}$ cycle, the pillared material showed a capacity 1.7 times that of the non-pillared material (131 compared to $76 \mathrm{mAh} \mathrm{g}^{-1}$ for the pillared and non-pillared material respectively). Impressively, between the $50^{\text {th }}$ and $100^{\text {th }}$ cycles, the pillared MXene retains $98.5 \%$ of its capacity, whereas the as-made MXene only retains 89\%. Furthermore, the pillared material also shows better coulombic efficiency than the non-pillared MXene (after the first cycle). It takes only 14 cycles for $\mathrm{Ti}_{3} \mathrm{C}_{2}-\mathrm{OH}-\mathrm{Si}-400$ to reach efficiencies greater than $99 \%$, whereas the as-made MXene takes over 40 cycles. It should be noted that the improved performance obtained in the pillared MXene can be ascribed to the enlarged interlayer spacing, rather than any capacity contribution via alloying processes from the $\mathrm{SiO}_{2}$. Ex-situ XPS results (Figure S11), revealed that the position of the Si peak does not change between OCV and full discharge. This is consistent with the $\mathrm{SiO}_{2}$ pillars being redox inactive, with purely structural benefits which allows the effect of the increased interlayer spacing on electrochemical performance to be studied without extra processes resulting from alloying for conversion reactions occurring, as has been seen in other reports. ${ }^{44}$

Both materials showed a significantly increased capacity on the first discharge compared to subsequent cycles, which is likely due to SEI (solid-electrolyte interphase) formation and irreversible 
reactions with the MXene functional groups. ${ }^{54}$ This is further supported by the CV data (Figure $7 \mathrm{~d}$ e), which shows several peaks corresponding to irreversible processes on the first cycle. This is discussed in more detail below. It is important to note that the pillared material reaches a stable capacity from the $2^{\text {nd }}$ cycle onwards, whereas the non-pillared one takes around five cycles to stop seeing rapid decreases between cycles (Figure 7c). The significantly higher initial discharge capacity in the pillared MXene compared to the first charge may be due to the irreversible reactions of $\mathrm{Na}$ or the electrolyte with the MXene surface groups, since more of the MXene surface will be accessible to the $\mathrm{Na}$ and electrolyte immediately. It is well known that electrode materials with high surface areas can suffer from low coulombic efficiencies on the first cycle due to the fact that there is a higher proportion of surface exposed to the electrolyte. ${ }^{55}$ This effect has also been observed in our previous work on pillared MXenes in other systems. ${ }^{56}$ That the pillared $\mathrm{Ti}_{3} \mathrm{C}_{2}$ reached stable cycling after just one cycle is consistent with the structure being already expanded, and fully wetted with the electrolyte on the first cycle. In contrast, in the non-pillared MXene, fresh surface may be exposed to the electrolyte due to expansion of the structure during the first few cycles. This large initial irreversible capacity led to a lower initial coulombic efficiency for the pillared material compared to the non-pillared one (57\% to $70 \%$ respectively). Nonetheless, $40-60 \%$ initial coulombic efficiencies are typical for $\mathrm{Ti}_{3} \mathrm{C}_{2}$ and $\mathrm{Li}$ and $\mathrm{Na}$ systems, so at $57 \%$ efficiency the pillared material is still amongst the highest reported. ${ }^{6}$ The improved coulombic efficiency over subsequent cycles in the pillared MXene is likely to be due to the enlarged interlayer spacing allowing for improved ion transport in and out of the structure, thus avoiding the trapping of $\mathrm{Na}^{+}$which is often seen in multilayer MXenes.

To study the electrochemical performance in more detail, cyclic voltammetry experiments were conducted on the pillared, $\mathrm{Ti}_{3} \mathrm{C}_{2}-\mathrm{OH}-\mathrm{Si}-400$, and unpillared, $\mathrm{Ti}_{3} \mathrm{C}_{2}-\mathrm{OH}-\mathrm{Si}-400$, samples. Figure 7 (d-e) shows the cyclic voltammograms at a scan rate of $0.2 \mathrm{mV} \mathrm{s}^{-1}$ in the voltage range of $0.01-3 \mathrm{~V} \mathrm{vs} . \mathrm{Na}^{+} /$ $\mathrm{Na}$. The non-pillared MXene shows clear anodic peaks at 2.1 and $0.3 \mathrm{~V}$ on the first cycle, with a small peak at $0.8 \mathrm{~V}$. These have previously been assigned to $\mathrm{Na}^{+}$intercalation, SEl formation and irreversible reactions between the MXene, $\mathrm{Na}^{+}$and/or the electrolyte and do not appear on subsequent cycles. For the pillared MXene, anodic peaks are observed at 0.8 and $0.3 \mathrm{~V}$, also corresponding to irreversible reactions and SEI formation. No peak is present above $2 \mathrm{~V}$. Over cycles 2-5, the non-pillared MXene displays clear redox peaks at 2.4 / $2.6 \mathrm{~V}$ (which has shifted from $2.1 \mathrm{~V}$ on the $1^{\text {st }}$ cycle) and $0.6 / 0.65 \mathrm{~V}$ (sodiation / desodiation). These have previously been assigned as $\mathrm{Na}^{+}$(de)-intercalation peaks, and equivalent peaks for $\mathrm{Li}^{+}$intercalation are also reported. ${ }^{54,57}$ There is a noticeable decrease in current across these cycles below $0.6 \mathrm{~V}$, which matches the loss of capacity seen in the load curves (Figure 7a). For the pillared MXene, no redox peaks are seen above $2 \mathrm{~V}$. Interestingly, in a report on the mechanism of $\mathrm{Ti}_{3} \mathrm{C}_{2}$ in lithium-ion batteries, Cheng et al. showed that increasing the interlayer spacing of the MXene with $\mathrm{NH}_{4}$ also caused the loss of the equivalent high voltage peak, which they linked to intercalation in narrow interlayer sites. ${ }^{57}$ This suggests that the loss of this peak is directly due to the enlarged interlayer spacing present in our pillared material. The lack of high voltage redox peaks contributes to the majority of current being below $1 \mathrm{~V}$ in the pillared material, which lowers the average potential of this electrode compared to the non-pillared material. A lower voltage is ideal for negative electrodes when used in a full cell since this maximises the overall cell energy density. This change is also reflected in the load curves (Figures $7 a-b)$ where the pillared MXene has a greater proportion of the capacity occurring under $1 \mathrm{~V}$ compared to the non-pillared MXene (which shows a more linear relationship between capacity and current, inductive of a more capacitive-like behaviour). The $\mathrm{CV}$ results also support the improved stability and capacity of the pillared MXene (Figure 7e), with less fade over cycles 2-4 and higher currents than the non-pillared MXene material. 
Furthermore, CV experiments were run at increasing rates from $0.2-5 \mathrm{mV} \mathrm{s}^{-1}$ to study the kinetics in both systems (Figure S12). For the non-pillared material the previously sharp redox peaks shift and broaden, giving a fairly rectangular (capacitive) shape at $5 \mathrm{mV} \mathrm{s}^{-1}$, suggesting poor intercalation kinetics at high rates. However, the low voltage peak was still clearly visible. The pillared material keeps its shape well at all rates but sees a shift in the $0.6 \mathrm{~V}$ peak to $1.5 \mathrm{~V}$ by $5 \mathrm{mV} \mathrm{s}^{-1}$ (shown by the arrow in Figure S12). It is known that the relationship between the current $(i)$ and scan rate $(v)$ is given by Equation 1:

$$
i=a v^{b}
$$

where $a$ and $b$ are fitting parameters ${ }^{58}$. Importantly, a $b$-value of 0.5 corresponds to a faradaic battery-like charge storage process and a $b$-value of 1 indicates a capacitive process. A plot of $\log (i)$ against $\log (v)$ gives a straight line with a slope of $b$. Following this analysis, the non-pillared material shows a $b$-value of 0.83 on the sodiation and 0.89 on desodiation (Figure S12). The pillared MXene has $b$-values of 0.67 (sodiation) and 0.71 (desodiation). This shows that for both materials charge storage occurs via a combination of mechanisms with contributions from both faradaic and capacitive processes. The pillared material shows significantly more current from faradic processes than the non-pillared material, likely due to increased exposure of redox active Ti which explains the higher capacity seen in this material. Importantly, rate capability testing (Figure 7f) shows that the pillared MXene maintains a superior performance at all rates tested (current densities of 20, 50, 200, $500,1,000 \mathrm{~mA} \mathrm{~g}^{-1}$ ). For example, the pillared material shows capacities of $96 \mathrm{mAh} \mathrm{g}^{-1}$ at $200 \mathrm{~mA} \mathrm{~g}^{-1}$ and $64 \mathrm{mAh} \mathrm{g}^{-1}$ at $500 \mathrm{~mA} \mathrm{~g}^{-1}$. In comparison, the non-pillared MXene has capacities of just $67 \mathrm{mAh} \mathrm{g}^{-}$ ${ }^{1}$ at $200 \mathrm{mAh} \mathrm{g}^{-1}$ and $49 \mathrm{~mA} \mathrm{~g}^{-1}$ at $500 \mathrm{~mA} \mathrm{~g}^{-1}$. This suggests that the faradic processes are fast, likely owing to easy ion transport within the pillared structure. Importantly, the capacity recovers back to $144 \mathrm{mAh} \mathrm{g}^{-1}$ when the rate is returned to $20 \mathrm{~mA} \mathrm{~g}^{-1}$, showing that the structure is not damaged by the high cycling rates. Overall, these results show that pillaring is an effective approach to improve the cycling stability of MXene electrodes and that the pillared MXene is well suited to Na-ion battery applications where low cost, long life and high power are essential. This is further emphasised by comparisons to previously reported Ti-based MXenes with enlarged interlayer spacings for $\mathrm{Na}$-ion applications (Table S3), which show that our $\mathrm{SiO}_{2}$-pillared $\mathrm{Ti}_{3} \mathrm{C}_{2}$ has capacities and stabilities among the highest reported without using alloying or conversion composites.

\section{Summary}

In conclusion, we have demonstrated the successful pillaring of $\mathrm{Ti}_{3} \mathrm{C}_{2}$ with low atomic number, inexpensive, earth-abundant silica-based pillars through an amine-assisted synthesis procedure. To our knowledge, this is the first report of silica-MXene composites, which was achieved without a pre-pillaring step, in contrast to the previous reports of Sn-pillaring of MXenes. It was shown that the choice of amine co-pillar and calcination temperature could be used to control the interlayer separation from 1.7 to $4.2 \mathrm{~nm}$, corresponding to a gallery height of $0.7 \mathrm{~nm}$ to $3.2 \mathrm{~nm}$, the latter being a $>10$-fold increase over the unpillared material, the largest interlayer spacing reported to date for any MXene, and one of the largest reported for any two-dimensional material. The pillaring also led to a substantial increase in BET surface areas (around 60 times larger than the non-pillared material), with the intercalated MXene showing a surface area of $235 \mathrm{~m}^{2} \mathrm{~g}^{-1}$, which is the highest surface area obtained for any MXene using an intercalation-based method. The detailed characterisation of the surface chemistry revealed the pillaring mechanism and provided insight into the interactions between the MXene surface termination groups, the amine co-pillar and the TEOS silica precursor. This allowed optimisation of the surface chemistryfor the reported pillaring method, using easily scalable wet chemical treatments. This methodology also provides a 
guide for the development and understanding of future techniques for the intercalation and pillaring of MXenes, and more widely on 2D materials. The pillared MXene was tested electrochemically as the negative electrode for a Na-ion battery system, and demonstrated superior capacity, rate capability and remarkable stability compared with the non-pillared materials. This is likely to result from the more open structure, with the pillars preventing the re-stacking of the MXene sheets. Crucially, for sodium-ion batteries, the material was extremely stable towards the reversible (de)intercalation of the large $\mathrm{Na}^{+}$ion, retaining $98.5 \%$ capacity between the $50^{\text {th }}$ and $100^{\text {th }}$ cycles. Further work is ongoing to fully understand the effect of the pillars on the electrochemical performance. This work widens the tools available to researchers attempting to modify MXenes for improved performance in a wide range of applications, as increased interlayer spacings and porosity are critical for applications far beyond electrochemical energy storage, including catalysis, gas separations and storage. We expect this report to stimulate further studies on new pillaring methods, on the creation of new highly stable porous MXenes and on the use of organometallic precursors to introduce novel chemistries to MXenes.

\section{Experimental Methods}

\section{Materials}

The following materials were used without any further purification: Titanium powder (-325 mesh, 99\% purity, Alfa Aesar), aluminium powder (-100+325 mesh, 99.5\% purity, Alfa Aesar), titanium carbide powder (-325 mesh, 98\% purity, Sigma Aldrich), sodium fluoride (99\% purity, Alfa Aesar), hydrochloric acid (37.5\% wt. Sigma Aldrich), tetraethylortho silicate (TEOS, 98\% purity, Alfa Aesar), 1-dodecylamine (DDA, 97\% purity, Alfa Aesar), n-octylamine ( $>98 \%$ purity, TCl Chemicals), octylamine ( $>98 \%$ purity, $\mathrm{TCl}$ Chemicals), , sodium hydroxide (97\% purity, pellets, Sigma Aldrich), NMethyl-2-pyrrolidone (NMP, 99.5\% purity, Alfa Aesar), PVDF (99.0\% purity, Alfa Aesar), Super P carbon black (99\% purity, Alfa Aesar), $\mathrm{NaPF}_{6}$ (99\% Alfa Aesar), diethyl carbonate (DEC) and ethylene carbonate (EC) (1:1 w/w\%, 99\% purity Gotion), Aluminium foil (Tob New Energy).

\section{Synthesis of $\mathrm{Ti}_{3} \mathrm{AlC}_{2}$}

For the synthesis of $\mathrm{Ti}_{3} \mathrm{AlC}_{2}, \mathrm{Ti}, \mathrm{Al}$ and $\mathrm{TiC}$ powders were mixed in a pestle and mortar in a 1:1.2:1.9 molar ratio. The mixture was then heated in a tube furnace under argon at $1,350{ }^{\circ} \mathrm{C}$ for $2 \mathrm{~h}$, with a heating rate of $5{ }^{\circ} \mathrm{C} \mathrm{min}-1$. The resulting lightly sintered block was then crushed with a pestle and mortar and ground to give a fine grey powder.

\section{Synthesis of $\mathrm{Ti}_{3} \mathrm{C}_{2} \mathrm{~T}_{\mathrm{x}}$}

To obtain the MXenes, $3 \mathrm{~g}$ of the as-synthesised $\mathrm{Ti}_{3} \mathrm{AlC}_{2}$ were sieved through a -400 mesh sieve (pore size of $38 \mu \mathrm{m})$ and added over $10 \mathrm{~min}$ to a $6 \mathrm{M} \mathrm{HCl}$ solution with pre-dissolved $\mathrm{NaF}$ (7.5:1 $\mathrm{F}$ to $\mathrm{Al}$ ratio). This mixture was heated to $40{ }^{\circ} \mathrm{C}$ and left to etch for $48 \mathrm{~h}$ with magnetic stirring. The acidic fluoride solution was then neutralised with $1 \mathrm{M} \mathrm{NaOH}(\mathrm{pH} 7-8)$ and vacuum filtered through borosilicate glass microfiber filter paper (pore size $45 \mu \mathrm{m}$, Cole-Parmer) to collect the black solid, which was dried overnight at $60^{\circ} \mathrm{C}$. NaF was chosen as the etching salt due to its significantly higher abundance and lower cost, which is more in keeping with the aims of Na-ion battery research than using LiF, which still requires the use of expensive lithium resources.

\section{Synthesis of $\mathrm{Ti}_{3} \mathrm{C}_{2}-\mathrm{OH}$ and $\mathrm{Ti}_{3} \mathrm{C}_{2}-\mathrm{O}$}

Previous reports have shown how the surface groups of $\mathrm{Ti}_{3} \mathrm{C}_{2}$ can be changed by different chemical treatment, with alkali treatments leading to a higher proportion of -O terminal groups compared to 
acid-treated ones. ${ }^{20,59}$ Therefore, two different washes were used to give two MXenes with different surface groups.

To obtain the MXene with a greater number of $-\mathrm{O}$ terminations, denoted $\mathrm{Ti}_{3} \mathrm{C}_{2}-\mathrm{O}$, the dried $\mathrm{Ti}_{3} \mathrm{C}_{2}$ powder was immersed in $1 \mathrm{M} \mathrm{NaOH}$ at room temperature for $4 \mathrm{~h}$. The powder was then recovered by vacuum filtration and washed with $\mathrm{DI}$ water. The resulting black powder was dried overnight at $60{ }^{\circ} \mathrm{C}$. For the MXene with the higher number of $\mathrm{OH}$ surface groups, denoted $\mathrm{Ti}_{3} \mathrm{C}_{2}-\mathrm{OH}$, the $\mathrm{NaOH}$ treated powder was then placed in $1 \mathrm{M} \mathrm{HCl}$ at room temperature for $4 \mathrm{~h}$ at room temperature. This was filtered, washed and dried in the same way as $\mathrm{Ti}_{3} \mathrm{C}_{2}-\mathrm{O}$.

\section{Pillaring of $\mathrm{Ti}_{3} \mathrm{C}_{2}$ samples}

For the pillaring experiments, $0.5 \mathrm{~g}$ of the $\mathrm{NaOH}$ or $\mathrm{HCl}$-treated MXene were added to a solution of dodecylamine (DDA) dissolved in TEOS in a MXene:DDA:TEOS molar ratio of 1:6-10:15-20 under argon. This was stirred in a sealed glass vial under argon at room temperature for $4 \mathrm{~h}$. The black powder was then recovered by vacuum filtration, dried on the filter paper under vacuum before being re-dispersed in $\mathrm{DI}$ water $(25 \mathrm{ml})$ overnight at room temperature $(18 \mathrm{~h})$. The intercalated product was then recovered by vacuum filtration and dried overnight at $60^{\circ} \mathrm{C}$. These samples were then calcined at either 300,400 or $500{ }^{\circ} \mathrm{C}$ for $2 \mathrm{~h}$ under argon with a heating rate of $5^{\circ} \mathrm{C} \mathrm{min}^{-1}$. Argon was used for the heat treatment steps instead of air (which would be expected to give more complete removal of the carbon template) to minimise the oxidation of the MXene. As can been seen from the thermal gravimetric analysis (TGA) results in Figure S13 in the Supporting Information, $\mathrm{Ti}_{3} \mathrm{C}_{2}$ is only stable in air up to $300^{\circ} \mathrm{C}$, before the mass starts to increase due to surface formation of $\mathrm{TiO}_{2}$ resulting from oxidation. This agrees with previous studies on the thermal stability of $\mathrm{Ti}_{3} \mathrm{C}_{2}$, which have shown oxidation at similarly low temperatures. ${ }^{51}$

For the pillaring using octylamine as the co-pillar, the same procedure was followed, using a molar ratio of MXene:OA:TEOS of 1:10:20. For the experiment using only TEOS for intercalation, the same procedure as described for the DDA assisted method was used, with a MXene:TEOS molar ratio of 1:20 used.

\section{Characterisation}

The samples were characterised by X-ray diffraction (XRD) in a Smartlab diffractometer (Rigaku, Tokyo, Japan) using $\mathrm{Cu} \mathrm{K \alpha}$ radiation operating in reflection mode with Bragg-Brentano geometry to investigate the crystal structure. Prior to the XRD characterisation, all samples were dried in a heated oven for $18 \mathrm{~h}$ at $80^{\circ} \mathrm{C}$. The black powders were then ground and placed on a silica sample holder and pressed flat with a glass slide.

Scanning electron microscopy (SEM) was done in a JEOL JSM-7800F (JEOL, Tokyo, Japan), and energy-dispersive $\mathrm{x}$-ray spectroscopy (EDX) was done in a X-Max50 (Oxford Instruments, Abingdon, UK) using an accelerating voltage of $10 \mathrm{kV}$ and a working distance of $10 \mathrm{~mm}$, which were used to study the morphology and elemental composition. For the SEM and SEM-EDS studies, the dried powder samples were dry cast onto a carbon tape support, which was placed on to a copper stub for analysis. For (S)TEM characterisation, each specimen was crushed using a mortar and pestle, dispersed in methanol and drop-cast onto holey carbon grids. They were then loaded into an FEI Tecnai TF30 (FEI-Thermo Fisher Scientific, Hillsboro, US) and imaged in high-angle annular dark field (HAADF)-STEM mode at $300 \mathrm{kV}$. STEM-EDS was conducted using an UltimMax detector (Oxford Instruments, Abingdon, UK). 
Thermal gravimetric analysis (TGA) was done in a STA 449 F3 Jupiter (Netzsch, Selb, Germany) to look at the effect of heat treatments on the intercalated and pillared sample. Small amounts of the dried MXene (20 to $30 \mathrm{mg}$ ) were placed into alumina crucibles which were then placed directly into the heated chamber of the TGA. Samples were then heated at a rate of $1{ }^{\circ} \mathrm{C} \mathrm{min}-1$ from $25^{\circ} \mathrm{C}$ to 700 ${ }^{\circ} \mathrm{C}$ under air or nitrogen. The BET method was used to determine the specific surface area of the materials and was measured in a Micromeritics ASAP 2020 (Micromeritics Instrument Corporation, Georgia, USA). Nuclear magnetic resonance (NMR), and Raman spectroscopy were used to study the $\mathrm{MXene}$ surface chemistry and interactions with the pillars. For the NMR studies, ${ }^{1} \mathrm{H},{ }^{19} \mathrm{~F},{ }^{13} \mathrm{C}$, and ${ }^{29} \mathrm{Si}$ solid-state NMR spectra were obtained at $16.4 \mathrm{~T}$ on a Bruker Advance $700 \mathrm{MHz}$ spectrometer (Bruker Biospin Corporation, Massachussetts, USA) operating at a Larmor frequencies of 700.1, $658.8,176.0$, and $139.0 \mathrm{MHz}$, respectively. Powdered samples were packed into $2.5 \mathrm{~mm}$ MAS rotors, and rotated at a MAS rate of $30 \mathrm{kHz}$ for most of the experiments. Further details are given in the supporting information (Table S4).

Raman spectroscopy was carried out on a Horiba Lab Raman Spectrometer (Horiba, Minami-ku Kyoto, Japan) with an EM-cooled Synapse camera. For taking spectra, a 100x, 0.90 NA microscope objective was used. The dried powder was sandwiched between two glass microscope slides which were pressed together to give flat MXene particles. One of these slides was then discarded, with the other slide placed flat under the diode laser $(532 \mathrm{~nm}, 200 \mu \mathrm{W})$ for measurements.

Gas sorption isotherms were measured on a Micromeritics ASAP 2020Plus gas sorption analyser using high purity nitrogen gas at $77 \mathrm{~K}$. BET surface areas were calculated over a relative pressure range of $0.05-0.15 \mathrm{P} / \mathrm{P}_{0}$. Pore size distributions were calculated using the NL-DFT method using a slit pore model.

Ex-situ XPS was performed on a Thermo Fisher Scientific NEXSA spectrometer. Samples were analysed using a micro-focused monochromatic Al x-ray source $(19.2 \mathrm{~W})$ over an area of approximately 100 microns. Data were recorded at pass energies of $150 \mathrm{eV}$ for survey scans and 40 $\mathrm{eV}$ for high resolution scan with $1 \mathrm{eV}$ and $0.1 \mathrm{eV}$ step sizes respectively. Charge neutralisation of the sample was achieved using a combination of both low energy electrons and argon ions. To remove any surface contaminants, cluster cleaning was performed with $2 \mathrm{keV}$ energy at $0.5 \times 0.5 \mathrm{~mm}$ area for $60 \mathrm{~s}$. The electrodes were extracted from the cell in an argon filled glovebox $\left(\mathrm{O}_{2}<0.1 \mathrm{ppm}, \mathrm{H}_{2} \mathrm{O}<\right.$ $0.1 \mathrm{ppm}$ ) at the desired state of charge, washed with the electrolyte solvent to remove surface salts, dried at room temperature under vacuum, and packed under argon before testing. A polypropylene membrane separator (Celgard) was used instead of a microfiber glass separator to minimise surface contamination from fibres.

\section{Electrochemical characterisation}

To test the effect of the pillaring process on the electrochemical performance, the pillared and unpillared materials were tested in a half cell configuration using sodium metal disks as the counter electrode and $1 \mathrm{M} \mathrm{NaPF}_{6}$ in EC/DEC (1:1 weight ratio) as the electrolyte. The MXene was mixed with carbon black (super $P$, company) as a conductive additive and PVDF as the binder in a 75:15:10 weight ratio respectively. These were added to NMP to make a slurry, which was then cast onto an aluminium foil current collector, from which electrodes with a diameter of $16 \mathrm{~mm}$ were punched. The active mass weighting was between 3 to $5 \mathrm{mg}$. CR2032 type coin cells were constructed in an argon filled glovebox $\left(\mathrm{O}_{2}\right.$ and $\mathrm{H}_{2} \mathrm{O}$ levels $\left.<0.1 \mathrm{ppm}\right)$ using Whatman micro glass fibre paper as the separator. The charge-discharge tests were carried out on a Neware battery cycler (Neware battery system, China) at a current density of $20 \mathrm{~mA} \mathrm{~g}^{-1}$ in the voltage range of 0.01-3 $\mathrm{V}$ for 100 cycles. For rate capability tests, the cells were cycled at a current density of $20 \mathrm{~mA} \mathrm{~g}^{-1}$ for 1 cycle to stabilise the 
cell before 5 cycles at each current density of 20, 50, 200, 500 and 1,000 mA g-1 were run before returning to $20 \mathrm{~mA} \mathrm{g^{-1 }}$. Cyclic voltammetry (CV) measurements were conducted using an Ivium potentiostat (Ivium Technologies BV, The Netherlands) with a scan rate of $0.2 \mathrm{mV} \mathrm{s}$ ${ }^{1}$ for 5 cycles, followed by further cycles at $0.5,2$ and $5 \mathrm{mV} \mathrm{s}^{-1}$ sweep rates in the voltage range of 0.01-3V.

\section{Acknowledgments}

The authors would like to thank L. Bouscarrat for his assistance with the MXene synthesis and N. Halcovitch and S. Baldock for assistance with XRD and SEM measurements. Lancaster University is thanked for provision of the NMR, SEM and XRD facilities, and for partially funding this research. Characterisation facilities were part funded by the European Regional Development Fund (ERDF) under the Collaborative Technology Access Program (cTAP). The work was supported by an Early Career Internal Grant from Lancaster University and departmental funding. PAM, DJK and SS gratefully acknowledge support from the EPSRC Graphene NOWNANO Centre for Doctoral Training. RJY acknowledges support by the Royal Society through a University Research Fellowship (Grants UF110555 and UF160721). NTR would like to acknowledge the Royal Society for the provision of a Research grant (RG2017 R2) to conduct the research described in this paper. S.J.H. thanks EPSRC grants EP/M010619/1 and EP/P009050/1, the European Research Council (ERC) under the European Union's Horizon 2020 research and innovation programme (Grant ERC-2016-STG-EvoluTEM-715502 and the ERC Synergy Hetero2D project). XPS data collection was performed at the EPSRC National Facility for XPS ('HarwellXPS'), operated by Cardiff University and UCL, under contract No. PR16195.

\section{Supporting information:}

Supporting Information Available: The Supporting Information includes further characterisation from EDS, XRD, SEM, IR spectroscopy and TGA for the MXene samples. This material is available free of charge.

\section{References}

1. Naguib, M. et al. Two-dimensional nanocrystals produced by exfoliation of Ti3 AlC2. Adv. Mater. 23, 4248-53 (2011).

2. Ghidiu, M., Lukatskaya, M. R., Zhao, M.-Q., Gogotsi, Y. \& Barsoum, M. W. Conductive twodimensional titanium carbide 'clay' with high volumetric capacitance. Nature 516, 78-81 (2014).

3. Harris, K. J., Bugnet, M., Naguib, M., Barsoum, M. W. \& Goward, G. R. Direct Measurement of Surface Termination Groups and Their Connectivity in the 2D MXene V 2 CT x Using NMR Spectroscopy. J. Phys. Chem. C 119, 13713-13720 (2015).

4. Chaudhari, N. K. et al. MXene: an emerging two-dimensional material for future energy conversion and storage applications. J. Mater. Chem. A 5, 24564-24579 (2017).

5. Lei, J.-C., Zhang, X. \& Zhou, Z. Recent advances in MXene: Preparation, properties, and applications. Front. Phys. 10, 276-286 (2015).

6. Pang, J. et al. Applications of 2D MXenes in energy conversion and storage systems. Chem. Soc. Rev. 48, 72-133 (2019).

7. Naguib, M., Mochalin, V. N., Barsoum, M. W. \& Gogotsi, Y. 25th anniversary article: MXenes: a new family of two-dimensional materials. Adv. Mater. 26, 992-1005 (2014).

8. Freytag, A. I., Pauric, A. D., Jiang, M. \& Goward, G. R. ${ }^{7}$ Li and ${ }^{29}$ Si NMR Enabled by High- 
Density Cellulose-Based Electrodes in the Lithiation Process in Silicon and Silicon Monoxide Anodes. J. Phys. Chem. C 123, 11362-11368 (2019).

9. Naguib, M. et al. MXene: a promising transition metal carbide anode for lithium-ion batteries. Electrochem. commun. 16, 61-64 (2012).

10. Ren, C. E. et al. Porous Two-Dimensional Transition Metal Carbide (MXene) Flakes for HighPerformance Li-Ion Storage. ChemElectroChem 3, 689-693 (2016).

11. Lin, Z. et al. Carbon nanofiber bridged two-dimensional titanium carbide as a superior anode for lithium-ion batteries. J. Mater. Chem. A 3, 14096-14100 (2015).

12. Raccichini, R., Varzi, A., Passerini, S. \& Scrosati, B. The role of graphene for electrochemical energy storage. Nat. Mater. 14, 271-9 (2015).

13. Pumera, M. Graphene-based nanomaterials for energy storage. Energy Environ. Sci. 4, 668674 (2011).

14. Sun, Y., Wu, Q. \& Shi, G. Graphene based new energy materials. Energy Environ. Sci. 4, 1113 (2011).

15. Mashtalir, O. et al. Intercalation and delamination of layered carbides and carbonitrides. Nat. Commun. 4, 1716 (2013).

16. Dall'Agnese, Y., Rozier, P., Taberna, P.-L., Gogotsi, Y. \& Simon, P. Capacitance of twodimensional titanium carbide (MXene) and MXene/carbon nanotube composites in organic electrolytes. J. Power Sources 306, 510-515 (2016).

17. Zhao, M.-Q. et al. Flexible MXene/carbon nanotube composite paper with high volumetric capacitance. Adv. Mater. 27, 339-45 (2015).

18. Xue, Q. et al. $\mathrm{Mn}_{3} \mathrm{O}_{4}$ nanoparticles on layer-structured $\mathrm{Ti}_{3} \mathrm{C}_{2} \mathrm{MXene}$ towards the oxygen reduction reaction and zinc-air batteries. J. Mater. Chem. A 5, 20818-20823 (2017).

19. Zhao, G. et al. Self-Assembled Sandwich-like MXene-Derived Nanocomposites for Enhanced Electromagnetic Wave Absorption. ACS Appl. Mater. Interfaces 10, 42925-42932 (2018).

20. Luo, J. et al. $\mathrm{Sn}^{4+}$ Ion Decorated Highly Conductive $\mathrm{Ti}_{3} \mathrm{C}_{2} \mathrm{MXene:} \mathrm{Promising} \mathrm{Lithium-Ion}$ Anodes with Enhanced Volumetric Capacity and Cyclic Performance. ACS Nano 10, 24912499 (2016).

21. Kloprogge, J. T. Synthesis of Smectites and Porous Pillared Clay Catalysts: A Review. J. Porous Mater. 5, 5-41 (1998).

22. Bhattacharyya, K. G. \& Gupta, S. Sen. Kaolinite, montmorillonite, and their modified derivatives as adsorbents for removal of $\mathrm{Cu}(\mathrm{II})$ from aqueous solution. Sep. Purif. Technol. 50, 388-397 (2006).

23. Park, K.-W., Jung, J. H., Kim, J. D., Kim, S.-K. \& Kwon, O.-Y. Preparation of mesoporous silicapillared H+-titanosilicates. Microporous Mesoporous Mater. 118, 100-105 (2009).

24. Luo, J. et al. Pillared Structure Design of MXene with Ultralarge Interlayer Spacing for HighPerformance Lithium-Ion Capacitors. ACS Nano 11, 2459-2469 (2017).

25. Xu, M. et al. Opening Magnesium Storage Capability of Two-Dimensional MXene by Intercalation of Cationic Surfactant. ACS Nano 12, 3733-3740 (2018).

26. Mashtalir, O., Lukatskaya, M. R., Zhao, M.-Q., Barsoum, M. W. \& Gogotsi, Y. Amine-Assisted Delamination of Nb2C MXene for Li-lon Energy Storage Devices. Adv. Mater. 27, 3501-6 
(2015).

27. Shen, L. et al. Carbon-intercalated $\mathrm{Ti}_{3} \mathrm{C}_{2} \mathrm{~T}_{\times} \mathrm{MXene}$ for high-performance electrochemical energy storage. J. Mater. Chem. A 6, 23513-23520 (2018).

28. Li, L. et al. Recent progress on sodium ion batteries: potential high-performance anodes. Energy Environ. Sci. 11, 2310-2340 (2018).

29. Peng, C., Wang, C.-A., Song, Y. \& Huang, Y. A novel simple method to stably synthesize Ti3AIC2 powder with high purity. Mater. Sci. Eng. A 428, 54-58 (2006).

30. Hu, T. et al. Vibrational properties of $\mathrm{Ti}_{3} \mathrm{C}_{2}$ and $\mathrm{Ti}_{3} \mathrm{C}_{2} \mathrm{~T}_{2}(\mathrm{~T}=\mathrm{O}, \mathrm{F}, \mathrm{OH})$ monosheets by firstprinciples calculations: a comparative study. Phys. Chem. Chem. Phys. 17, 9997-10003 (2015).

31. Hu, M. et al. High-Capacitance Mechanism for $\mathrm{Ti}_{3} \mathrm{C}_{2} T_{\times}$MXene by in Situ Electrochemical Raman Spectroscopy Investigation. ACS Nano 10, 11344-11350 (2016).

32. Da, Y. et al. Engineering 2D Architectures toward High-Performance Micro-Supercapacitors. Adv. Mater. 31, 1802793 (2019).

33. Xue, Y. et al. Opening Two-Dimensional Materials for Energy Conversion and Storage: A Concept. Adv. Energy Mater. 7, 1602684 (2017).

34. Gong, S., Zhao, G., Lyu, P. \& Sun, K. A Pseudolayered $\mathrm{MoS}_{2}$ as Li-lon Intercalation Host with Enhanced Rate Capability and Durability. Small 14, 1803344 (2018).

35. Bourlinos, A. B. et al. Graphite Oxide: Chemical Reduction to Graphite and Surface Modification with Primary Aliphatic Amines and Amino Acids. Langmuir 19, 6050-6055 (2003).

36. Banda, H. et al. Investigation of ion transport in chemically tuned pillared graphene materials through electrochemical impedance analysis. Electrochim. Acta 296, 882-890 (2019).

37. Margarita Herrera-Alonso, Ahmed A. Abdala, †, Michael J. McAllister, Ilhan A. Aksay, A. \& Prud'homme*, R. K. Intercalation and Stitching of Graphite Oxide with Diaminoalkanes. Langmuir 23, 10644-10649 (2007).

38. Yuan, K. et al. Straightforward Generation of Pillared, Microporous Graphene Frameworks for Use in Supercapacitors. Adv. Mater. 27, 6714-6721 (2015).

39. Banda, H. et al. Ion Sieving Effects in Chemically Tuned Pillared Graphene Materials for Electrochemical Capacitors. Chem. Mater. 30, 3040-3047 (2018).

40. Banda, H. et al. Sparsely Pillared Graphene Materials for High-Performance Supercapacitors: Improving Ion Transport and Storage Capacity. ACS Nano 13, 1443-1453 (2019).

41. Luo, J. et al. Tunable pseudocapacitance storage of MXene by cation pillaring for high performance sodium-ion capacitors. J. Mater. Chem. A 6, 7794-7806 (2018).

42. Tian, W. et al. Layer-by-layer self-assembly of pillared two-dimensional multilayers. Nat. Commun. 10, 1-10 (2019).

43. Xie, X. et al. Porous Heterostructured MXene/Carbon Nanotube Composite Paper with High Volumetric Capacity for Sodium-Based Energy Storage Devices. Nano Energy (2016) doi:10.1016/j.nanoen.2016.06.005.

44. Luo, J. et al. Pillared MXene with Ultralarge Interlayer Spacing as a Stable Matrix for High Performance Sodium Metal Anodes. Adv. Funct. Mater. 29, 1805946 (2019). 
45. Luo, J. et al. Pillared Structure Design of MXene with Ultralarge Interlayer Spacing for HighPerformance Lithium-Ion Capacitors. ACS Nano 11, 2459-2469 (2017).

46. Shen, L. et al. Carbon-intercalated Ti $3 \mathrm{C} 2 \mathrm{~T} \times \mathrm{MXene}$ for high-performance electrochemical energy storage. J. Mater. Chem. A 6, 23513-23520 (2018).

47. Paek, S.-M., Jung, H., Park, M., Lee, J.-K. \& Choy, J.-H. An Inorganic Nanohybrid with High Specific Surface Area: TiO 2 -Pillared MoS 2. Chem. Mater. 17, 3492-3498 (2005).

48. Bao, W. et al. Porous Cryo-Dried MXene for Efficient Capacitive Deionization. Joule 2, 778787 (2018).

49. Thommes, M. et al. Physisorption of gases, with special reference to the evaluation of surface area and pore size distribution (IUPAC Technical Report). Pure Appl. Chem. 87, 1051-1069 (2015).

50. Hope, M. A. et al. NMR reveals the surface functionalisation of Ti3C2 MXene. Phys. Chem. Chem. Phys. 18, 5099-102 (2016).

51. Li, Y., Deng, X., Tian, J., Liang, Z. \& Cui, H. Ti3C2 MXene-derived Ti3C2/TiO2 nanoflowers for noble-metal-free photocatalytic overall water splitting. Appl. Mater. Today 13, 217-227 (2018).

52. Su, X. et al. Effects of etching temperature and ball milling on the preparation and capacitance of Ti3C2 MXene. J. Alloys Compd. 752, 32-39 (2018).

53. Kwon, O.-Y., Shin, H.-S. \& Choi, S.-W. Preparation of Porous Silica-Pillared Layered Phase: Simultaneous Intercalation of Amine-Tetraethylorthosilicate into the $\mathrm{H}+-$ Magadiite and Intragallery Amine-Catalyzed Hydrolysis of Tetraethylorthosilicate. Chem. Mater. 12, 12731278 (2000).

54. Kajiyama, S. et al. Sodium-Ion Intercalation Mechanism in MXene Nanosheets. ACS Nano 10, 3334-3341 (2016).

55. Sun, Y., Liu, N. \& Cui, Y. Promises and challenges of nanomaterials for lithium-based rechargeable batteries. Nature Energy vol. 1 1-12 (2016).

56. Maughan, P. A., Tapia-Ruiz, N. \& Bimbo, N. In-situ pillared MXene as a viable zinc-ion hybrid capacitor. Electrochim. Acta 341, 136061 (2020).

57. Cheng, R. et al. Understanding the Lithium Storage Mechanism of Ti3C2Tx MXene. J. Phys. Chem. C 123, 1099-1109 (2019).

58. Augustyn, V. et al. High-rate electrochemical energy storage through Li+ intercalation pseudocapacitance. Nat. Mater. 12, 518-522 (2013).

59. Peng, Q. et al. Unique Lead Adsorption Behavior of Activated Hydroxyl Group in TwoDimensional Titanium Carbide. J. Am. Chem. Soc. 136, 4113-4116 (2014). 
Table of Contents Graphic

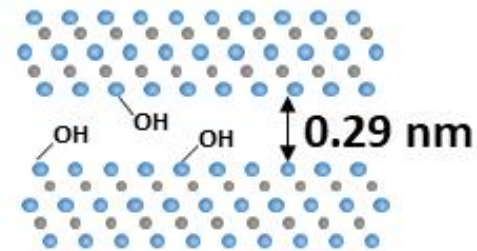

MXene

$\mathrm{Ti}_{3} \mathrm{C}_{2}-\mathrm{OH}$

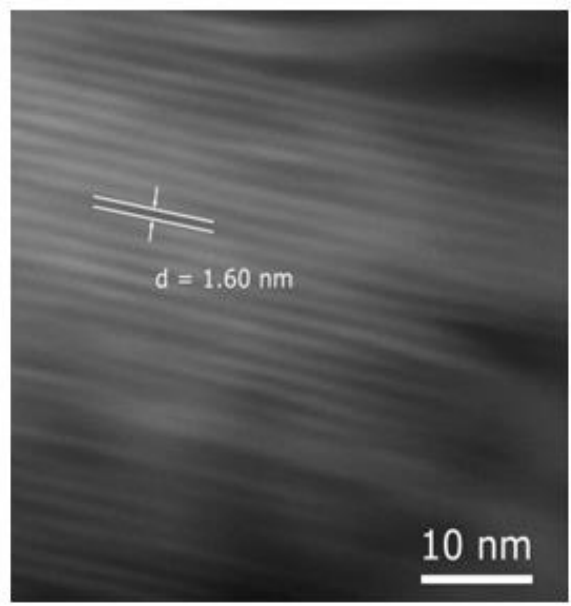

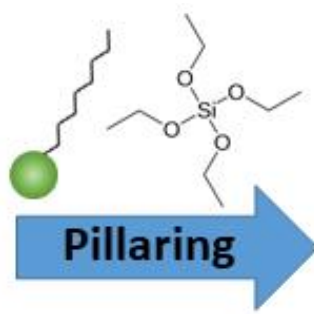

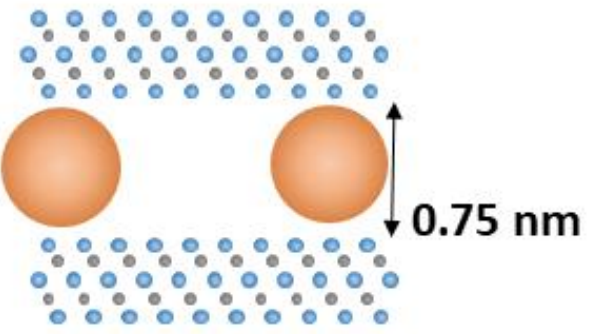

Pillared MXene

$\mathrm{Ti}_{3} \mathrm{C}_{2}$-OH-Si-400

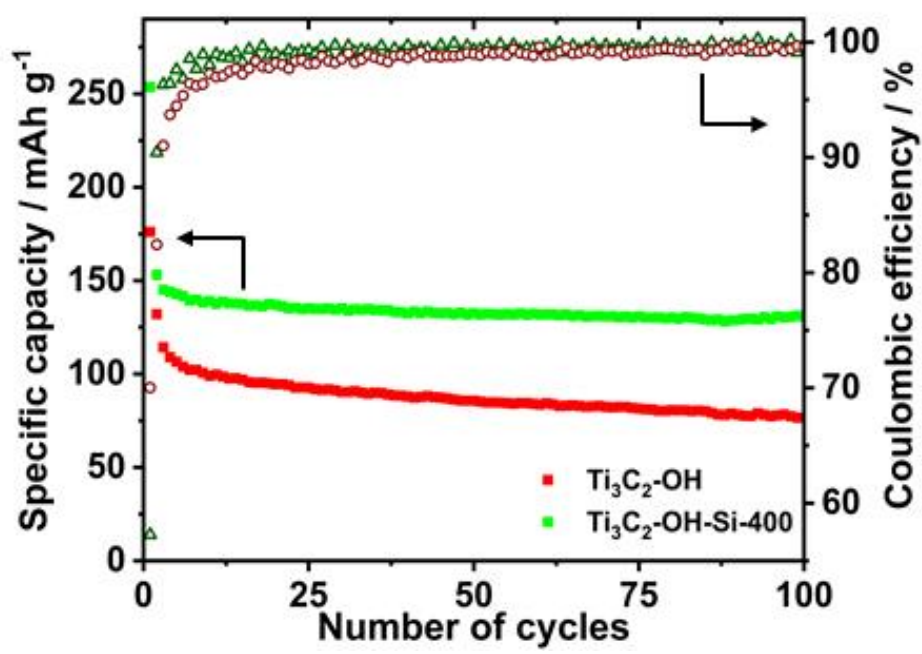

